\title{
NUEVOS PERFILES DEL DERECHO AL OLVIDO EN EUROPA Y ESPAÑA
}

\author{
NEW PROFILES OF THE RIGHT TO BE FORGOTTEN \\ IN EUROPE AND SPAIN
}

\author{
MÓNICA MARTÍNEZ LÓPEZ-SÁEZ \\ Universitat de València
}

Recibido: 07/06/2017
Aceptado: 10/10/2017

Resumen: Las nuevas tecnologías generan amenazas y retos asociados a los derechos fundamentales, especialmente aquellos relativos a la vida privada. Una de estas amenazas, propia de la naturaleza del mundo digital, es la total ausencia de límites espacio-temporales, la cual genera una permanencia de datos potencialmente perjudiciales y universalmente accesibles en Internet. Como solución al problema se ha planteado reconocer y regular el omnipresente y controvertido "derecho al olvido", entendiéndolo como un derecho a borrar, ocultar e incluso cancelar los datos personales vinculados a hechos pasados que puedan afectar a la dignidad y el libre desarrollo de la persona. El presente artículo acomete el estudio de los recientes desarrollos normativos y jurisprudenciales relativos al reconocimiento y régimen jurídico del denominado derecho al olvido a tres niveles (CdE-UE-España) desde una perspectiva constitucional, dentro del marco jurídico de la protección de datos en Europa, así como de los retos futuros a los que se enfrentará.

Palabras clave: Derecho al olvido; Memoria digital; Protección de datos; Derecho Constitucional; Europa.

\begin{abstract}
Emerging technologies pose new threats and challenges associated with fundamental rights, in particular the right to privacy. One of these threats, specific to the nature of the digital realm, is the total absence of temporal and spatial limits, which reinforces the indelible nature of potentially harmful and universally accessible online data. As a solution to the aforementioned problem, the possibility of recognising and regulating the controversial "right to be forgotten" was envisaged and carried out, understanding said right as the right to delete, hide or even cancel personal data linked to past events that may affect the dignity or the free personal development of the personality. This article focuses on the study of both recent normative and case-law developments regarding the recognition and legal paradigm of the so-called right to oblivion or right to be forgotten, through a three-level analysis (CoE, EU, Spain) from a Constitutional Law perspective, within the data protection policy framework in Europe, as well as some of the future internal and global challenges it will pose.
\end{abstract}

Key words: Right to be forgotten; Digital Memory; Data Protection; Constitutional Law; Europe.

SUMARIO: 1.CONSIDERACIONESINTRODUCTORIAS:LASNUEVASTECNOLOGÍAS Y SU INCIDENCIA EN LA CONFIGURACIÓN DE UN DERECHO AL OLVIDO DIGITAL. 2. LA COMPLEJIDAD DEL ENTRAMADO NORMATIVO RELATIVO AL DERECHO AL OLVIDO: 2.1. Consagración de la base normativa en el seno del Consejo de Europa. 2.2. Reforza- 
miento de la base normativa en el seno de la Unión Europea. 2.3. Desarrollos y adaptaciones normativas en España. 3. AVANCES JURISPRUDENCIALES EN MATERIA DEL DERECHO AL OLVIDO: 3.1. Líneas desarrolladas por el TEDH y el CEDS. 3.2. Jurisprudencia específica del TJUE. 3.3. Aportaciones recientes de la jurisdicción española. 4. REFLEXIONES Y PROPUESTAS FINALES. EL YO PROTÉICO FRENTE A LA RED QUE NUNCA OLVIDA Y LA DIFICIL BÚSQUEDA DE UN EQUILIBRIO COMO RETO CONSTITUCIONAL.

\section{CONSIDERACIONES INTRODUCTORIAS: LAS NUEVAS TEC- NOLOGÍAS Y SU INCIDENCIA EN LA CONFIGURACIÓN DE UN DERECHO AL OLVIDO DIGITAL}

El ritmo acelerado de la constante innovación tecnológica y la imparable transformación digital, ha marcado y cambiado radicalmente la escala y el modo en que se intercambian y se utilizan los datos, creando una nueva realidad socio-digital ${ }^{1}$, favoreciendo el almacenamiento, procesamiento y transmisión masiva de información y transformando así la economía y la sociedad. Entre los elementos principales y originarios de la era digital, cabe destacar la desaparición de la distancia espaciotemporal en la creación y difusión de los contenidos en la Red Internet, como consecuencia de los avances tecnológicos, tanto en la esfera del hardware como en la del software, del desarrollo y proliferación de los motores de búsqueda y del auge de las libertades informativas, entre otros muchos. No obstante, el desarrollo tecnológico y digital han sobrepasado las fronteras incluso de nuestra imaginación. En efecto, la tecnología y la transformación digital en particular han avanzado y siguen avanzando a una velocidad sin precedentes, afectando a todas las facetas de la vida cotidiana. Ya no hablamos simplemente del Internet de las Cosas, de la ciberseguridad, de las redes sociales o del comercio electrónico, sino que hemos pasado al Business Intelligence $^{2}$, al Neuro-marketing ${ }^{3}$, al Cloud Computing, al Big Data ${ }^{4}$ o a invenciones que ya no son propias de la ciencia ficción como son la robótica y la Inteligencia Artificial.La innovación tecnológica y digital está restructurando el funcionamiento de los individuos, las empresas y las sociedades modernas. La información se ha convertido ya no sólo en poder sino en dinero. Hay mercados específicos que dependen, en su práctica totalidad, de datos de carácter personal ${ }^{5}$, favoreciendo el almacenamien-

J. M. CEREZO, "Hacia un nuevo paradigma. La era de la información fragmentada", Revista TELOS, n.o 76 (julio-septiembre), 2008, pp. 1-8.

2 R. SABHERWAL e I. BECERRA-FERNANDEZ, Business Intelligence Practices, Technologies and Management, Hoboken, John Wiley \& Sons, 2011, pp. 6-8.

3 S. STANTON, "Neuromarketing: Ethical Implications of its Use and Potential Misuse", Journal of Business Ethics, 2016, pp. 1-13.

4 Desde sus orígenes con V. MAYER-SCHÖNBERGER y K. CUKIER, Big Data: A Revolution That Will Transform How We Live, Work, and Think, John Murray Publishers, Londres, 2013; hasta su análisis actual con R. MARTÍNEZ MARTÍNEZ, "Cuestiones de ética jurídica al abordar proyectos de Big Data. El contexto del Reglamento general de protección de datos", Dilemata n.o. 24, 2017, 151-164.

A. ACQUISTI, Alessandro, C. TAYLOR y L. WAGMAN, "The economics of privacy", Journal of Economic Literature, n.o. 54: 2, 2016, pp. 442-492. 
to, procesamiento y transmisión masiva de información personal. Así, a pesar de la gran oferta de oportunidades con las que garantizar un progreso social y económico, facilitando la vida diaria en todas sus facetas, el diseño y dependencia de la NTIC también las convierte en fuente de vulnerabilidad, para los estados (seguridad), las empresas (competitividad) y el conjunto de la ciudadanía (privacidad).

Este nuevo entorno digital ha supuesto la creación y difusión instantánea e universal $^{6}$ de la información, y por tanto, como consecuencia natural, también ha conllevado una indeleble perennidad de la información almacenada, publicada y compartida en Internet, dado que la información se difunde, a menudo allende la voluntad del emisor y permanece en Internet, mientras que el efecto multiplicador y perfeccionador de los motores de búsqueda facilita suidentificación, clasificación y distribución inmediatas y casi irrestrictas.Así, en una era como la actual, en la que la memoria está relegada a infinidad de bancos de datos y a la apertura de una gama de posibilidades que permite el almacenamiento por tiempo indefinido de los datos, asistimos al estreno, nunca antes visto, de la llamada "memoria digital". Esta memoria, en nuestra opinión, está compuesta por dos rasgos característicos. En primer lugar, se trata de una memoria que almacena no sólo toda la información generada por los usuarios de forma manual o directa, sino también toda aquella información generada por su comportamiento ${ }^{7}$. En segundo lugar, se trata de una memoria que trasciende los límites de la memoria humana, diseñada ingeniosamente con la capacidad de olvidar. Centrándonos en este segundo rasgo, es cierto que hasta la revolución digital, la información se materializaba y expresaba de una manera concreta y manejable, dependiendo ineludiblemente del paso del tiempo para su gradual pérdida u olvido. Sin embargo, nuestra memoria ya no está únicamente instalada en nuestro interior ${ }^{8}$ pues las actuales tecnologías amplían nuestras memorias en forma de bytes almacenados en dispositivos físicos o en realidades virtuales, que hacen que nuestros recuerdos se conserven de manera exacta e indefinida incluso más allá de nuestro propio olvido ${ }^{9}$.En efecto, como han apuntado grandes especialistas en la materia, históricamente el olvido era la regla y la memoria la excepción, pero hoy en día la tecnología "[...] lleva a la humanidad a la memoria como principio y al olvido solo por defecto. Esta y no otra causa explica y justifica la imperiosa e insistente

6 P. SIMÓN CASTELLANO, El régimen constitucional del derecho al olvido digital, Tirant lo Blanch, Valencia, 2012, p. 38.

7 J. ARANDA SERRALBO, Right to oblivion: A way to get to know ourselves and share the knowledge, Londres, 2013, p. 47.

8 En el hipocampo (remota) y en la corteza prefrontal (inmediata). En efecto, los procesos humanos de memoria dependen de la transición de la memoria próxima a la remota, sea por impacto o repetición, contrario a los mecanismos automáticos de las máquinas, y es justo aquí, en un enfoque humano de las redes frente a un enfoque "máquina" dónde se produce el elemento diferenciador crucial: las personas memorizamos y olvidamos selectivamente según nuestra propia identidad y nuestras experiencias particulares, mientras que las máquinas memorizan todo y no olvidan nada.

"Si algo han dado Google y compañía a la causa de la vida es precisamente eso, memoria. La información siempre ha existido, pero su acceso y localización nunca habían sido tan rápidos y sencillos como en la actualidad", vid. A. TOURIÑO, El derecho al olvido y a la intimidad en internet, Los Libros de la Catarata, Madrid, 2014, p. 24. 
demanda de desaparición de informaciones personales en la Red que se cobija bajo la expresión derecho al olvido en Internet" ${ }^{\prime 10}$.

El problema del olvido, expresado, de manera simplista, en el actual debate jurídico, como la supresión de datos, aparece ahora como un asunto controvertido, sobre todo porque muchas de las tecnologías de las que estamos requiriendo el olvido, no están diseñadas para olvidar; podría decirse que, de algún modo, olvidar es contrario a su naturaleza. En efecto, la infalibilidad de la memoria absoluta de Internet se contradice con los límites de la memoria humana, lo que necesariamente significa que las huellas que dejamos en el mundo digital, permanezcan y nos sigan, como una sombra ${ }^{11}$, dondequiera que vayamos. La memoria digital rechaza el elemento del tiempo, tan arraigado en nuestra propia existencia, pues impide que las personas se separen de su pasado, lo que, a su vez, evita un crecimiento y desarrollo humano saludable. En otras palabras, debido al mal moderno de perennidad y "superinformación" en la Red Internet, se conservan todo tipo de recuerdos: "los buenos, los feos y los malos'. En este contexto, no es de extrañar que los avances tecnológicos y, en concreto, los digitales, hayan generado no pocas preocupaciones sobre el impacto de dichos progresos en el aumento nunca de riesgos potenciales para los derechos fundamentales ${ }^{12}$, trayendo consigo nuevos retos para su ponderación y efectiva protección. Sin duda, esta nueva realidad socio-digital plantea verdaderos problemas en lo relativo a la tutela de los derechos fundamentales ${ }^{13} \mathrm{y}$, de manera más genérica, puede suponer una hipoteca para el libre desarrollo de la personalidad ${ }^{14} \mathrm{y}$, como sostendremos en este trabajo, para la dignidad de la persona.

La realidad tan cambiante, a efectos técnicos y sociales, y el consiguiente reto para el Derecho de regular estas nuevas situaciones y proteger de manera más efectiva los derechos relacionados con la intimidad y la vida privada se ve, de manera clara, con el auge de las nuevas tecnologías ${ }^{15}$. Internet, como receptor de información, puede a su vez convertirse en proveedor de la misma cuando la difunde o sim-

10 A. RALLO LOMBARTE, El derecho al olvido en Internet. Google versus España, Madrid, Centro de Estudios Políticos y Constitucionales, 2014, p. 17.

11 A. GHEZZI, A. GUIMARES PEREIRA y L. VESNIC-ALUJEVIC, The ethics of memory in a digital age: interrogating the right to be forgotten, Londres, Palgrave Macmillan memory studies, 2014, p. 11.

12 El barómetro del mes de febrero de 2017 del Centro de Investigaciones Sociológicas nos indica que más de la mitad, de los españoles encuestados están preocupados por el uso que otros hacen de sus datos. Disponible en: http://www.cis.es/cis/export/sites/default/-Archivos/Marginales/3160_3179/3168/es3168mar.pdf

13 Tales como el derecho al honor, el derecho a la vida privada y familiar, el derecho a la intimidad, el derecho a la propia imagen, el derecho a la protección de datos.

14 P. SIMÓN CASTELLANO, P., El régimen constitucional, cit., p. 21.

15 A.E. PEREZ LUÑO, Derechos humanos, Estado de Derecho y Constitución, $10^{\mathrm{a}}$ ed., Madrid, Tecnos, 2010, p. 361: "“en etapas anteriores, el respeto a la vida privada [...] permanecía así dentro de los límites de las relaciones naturales. Los muros de una casa, la soledad de un lugar desierto, incluso el tono expresivo oral del susurro, eran suficientes para asegurar [...] la intimidad [...] hoy es posible observar y escuchar a distancia, sin límites de tiempo, de espacio o de modo [...] estas circunstancias, en especial la utilización masiva de la informática, han deter- 
plemente habilita su visualización a los internautas ${ }^{16}$. Además, la forma en la que la sociedad actual entiende la vida y el día a día ha cambiado radicalmente: ya no es significativo, ni mucho menos fácil, distinguir entre lo offline y lo online en un mundo que tiende a estar constantemente interconectado y que exige transparencia absoluta. A su vez, las informaciones que se introducen en la World Wide Web, no son filtradas por profesionales ni por un código deontológico ${ }^{17}$, convirtiendo Internet en un medio de información independiente, complejo, descentralizado, abierto, e ilimitado. En este sentido, Internet, dotado de un incontrolable cúmulo de datos, habilita la búsqueda inmediata, puesta a disposición y relación de información, así como la creación de perfiles personales, poniendo en peligro la salvaguardia de los derechos de las personas. Así pues, nos encontramos que el refugio que suponían, antaño, las paredes, las puertas y los pensamientos, a día de hoy, ha sido ametrallado por infinitos cables, señales WiFi, cookies, nubes, y un sinfín de innovadoras maneras de almacenar, difundir y sacarle (en ocasiones indebido) provecho a la información personal.Y es precisamente, ante este nuevo panorama en el que la relación entre el ser humano, la ciencia y la tecnología ${ }^{18}$ se hace más estrecha, que ha surgido la obligación del legislador y del juez-intérprete a dar respuestas adecuadas a los riesgos existentes para la protección de los derechos fundamentales de las personas en la era del imparable avance de las NTIC, y, como apuntan algunos autores, a los riesgos relativos a una "expropiación sin precedentes de la privacidad" 19.

Como posible solución a estos problemas, se ha planteado regular un derecho al olvido digital, entendiéndolo como un derecho a ocultar, cancelar, e incluso borrar los datos personales vinculados a hechos pasados que puedan afectar al libre desarrollo de ciertos derechos fundamentales ${ }^{20}$. En esencia, es el derecho a la vida privada de las personas extendido a su uso de la Web (semánticamente e históricamente diferenciado pero cotidianamente asimilado al privacy americano ${ }^{21}$ ). Funciona, por tanto, como un concepto jurídico vinculado al Habeas Data y a la protección

minado que [...]constituya un problema nodal el establecimiento de unas garantías que tutelen [...] la agresión tecnológica a su intimidad”.

16 Para un análisis más exhaustivo del cambio de paradigma de lo supone Internet, sobre todo en lo relativo a los cambios en los modelos de comunicación, vid. M. DEL FRESNO GARCÍA, "Internet como macromedio. La cohabitación entre medios sociales y medios profesionales", TELOS: Cuadernos de comunicación e innovación, n.o. 99, 2014, (octubre-enero), pp. 107-109.

17 D. CÓRDOBA CASTROVERDE e I. DÍEZ-PICAZO GIMÉNEZ, "Reflexiones sobre los retos de la protección de la privacidad en un entorno tecnológico", Cuadernos y Debates, n.o. 248: El derecho a la privacidad en un nuevo entorno tecnológico, Madrid, Centro de Estudios Políticos y Constitucionales, 2016, p. 107.

18 S. RODOTÀ, El derecho a tener derechos, Bolonia, Trotta, Trad. de J. REVUELTA LÓPEZ, 2014, p. 172.

19 M. SANCHO LÓPEZ, "Nuevas amenazas para la protección de datos en el contexto del Big Data", Revista Aranzadi de Derecho y Nuevas Tecnologías, n.o. 43 (enero-abril), 2017, p. 5.

20 Olvido, que, por el mero paso del tiempo, como hemos apuntado, no sucede motu proprio en la red, por la visibilidad que otorga a la información en línea, que perpetúa los hechos pasados de modo generalmente irrestricto.

21 Para un análisis detallado de la confusión y ambigüedad terminológica entre los conceptos de "vida privada", "intimidad" y "privacidad" véase A. NOAIN SÁNCHEZ, La protección de 
de datos personales y constituye un nuevo mecanismo real que garantiza el control de los datos y la información visible en la red. El 'nacimiento' del llamado derecho al olvido en la red, que cobró un inusual protagonismo entre el 2013 y 2014, viene generando amplia discusión académica en lo relativo a su alcance y aplicación ${ }^{22}$. La privacidad en los últimos años ha visto modificada la percepción que de ella se tiene por la evolución tecnológica en el contexto de la sociedad de la información, pues la proliferación de nuevas tecnologías ha ampliado los umbrales de la tolerancia pública ante la intromisión en la esfera privada y personal. Además, una de las mayores preocupaciones respecto a las amenazas a la libertad de expresión e información en la red y a la transparencia son potenciales manipulaciones y censuras ${ }^{23}$. A partir de la Sentencia de 13 de mayo de 2014 (Google Spain, SL, Asunto C-131/12), se ha abordado el controvertido tema del derecho al olvido digital y, con el nuevo Reglamento general de protección de datos a nivel europeo, que reconoce jurídicamente un "derecho al olvido", se han desarrollado vertientes doctrinales que han estudiado la regulación general del mismo ${ }^{24}$, la extensión del propio Reglamento a nivel europeo ${ }^{25}$ y su proceso de reforma en España ${ }^{26}$ y en Europa ${ }^{27}$ así como los problemas inherentes a la puesta en práctica de esta cuestión ${ }^{28}$.

El respeto a la vida privada y a sus valores se encuentra muy arraigado en nuestra tradición jurídica civilista y se muestra inseparable de la existencia del individuo y el ejercicio de sus libertades. Algunos han afirmado que el derecho al olvido encuentra sus orígenes en el derecho a la intimidad ${ }^{29}$, en el derecho a

la intimidad y vida privada en internet: la integridad contextual y los flujos de información en las redes sociales (2004-2014), Agencia Española de Protección de Datos, Madrid, 2016, p. 77-106.

22 A. AZURMENDI, "Por un derecho al olvido para los europeos: aportaciones jurisprudenciales de la Sentencia del Tribunal de Justicia Europeo del caso Google Spain y su recepción por la Sentencia de la Audiencia Nacional Española de 29 de diciembre de 2014", Revista de Derecho Político (UNED), n.o 92, 2015, pp. 273-310.

${ }_{23}$ M.B. LÓPEZ PORTAS, "La configuración jurídica del derecho al olvido en el derecho español a tenor de la doctrina del TJUE”, Revista de Derecho Político (UNED), n.o 93 (mayoagosto), 2015, p. 147.

24 D. ORDOÑEZ SOLÍS, La protección judicial de los derechos en internet en la jurisprudencia europea, Reus, Madrid, 2014, p. 22.

25 A.TRONCOSO REIGADA, "El derecho al olvido en Internet a la luz de la propuesta de Reglamento General de Protección de Datos Personales", Revista de la Agencia de Protección de Datos de la Comunidad de Madrid, n.o 59, 2012, pp. 62-74.

26 P. SIMÓN CASTELLANO, El reconocimiento del derecho al olvido digital en España y en la UE. Efectos tras la sentencia del TJUE de mayo de 2014, Bosch, Barcelona, 2015, p. 300-302.

27 R.M. ORZA LLINARES y S. RUIZ TARRÍAS, "El derecho al olvido en Internet" en A. Cerrillo I Martinez, M. Peguera, I. Peña López y M. Vilasau Solana (Coords.), Neutralidad de la red y otros retos para el futuro de Internet, UOC-Huygens, Barcelona, 2011, pp. 380-389.

28 Para un estudio más exhaustivo sobre la complejidad en la aplicación del derecho al olvido, vid. R. MARTÍNEZ MARTÍNEZ, “¿Quién debería olvidarnos en Internet?”, Revista jurídica Aranzadi, n.o.857, 2013, p. 11; y R. MARTÍNEZ MARTÍNEZ, "Aplicar el derecho al olvido", Revista Aranzadi de Derecho y Nuevas Tecnologías, n.o. 36, 2014, pp. 121-142.

29 Para un análisis exhaustivo del derecho a la intimidad, y concreciones sobre la "intimidad informática", vid. L. REBOLLO DELGADO, El derecho fundamental a la intimidad, Dykinson, Madrid, 2005, p. 365. 
la vida privada y en el derecho a la protección de datos, o, en otras palabras, que deriva de $\operatorname{estos}^{30}$. Si bien es cierto que la facultad de actuación jurídica insertada en el contenido de otros derechos ya reconocidos ha servido de justificación para el posicionamiento jurídico y la naturaleza del derecho al olvido digital (pues los supracitados derechos "tradicionales" son, a fin de cuentas, derechos sobre los que repercute el tratamiento de información), este se materializa en Europa como un derecho vinculado al derecho fundamental a la protección de datos en tanto en cuanto garantía que va más allá de la oposición, pues la supresión por parte del afectado constituye el núcleo esencial del olvido. En estas coordenadas, algunos autores han expresado que el derecho al olvido nació muerto ${ }^{31}$; algunos otros lo califican como una acción de impedir la indexación de la información personal amparada en la voluntad individual de que la misma no sea conocida ${ }^{32}$; otros hablan del derecho al olvido como un mero instrumento jurídico vinculado a un derecho procesal a la protección de datos o a su garantía en el derecho de cancelación ${ }^{33} ; \mathrm{y}$, en fin, otros lo consideran como una prolongación del derecho a la intimidad ${ }^{34}$. Ahora bien, a través del estudio de los desarrollos normativos y jurisprudenciales en Europa y en España, sobre todo los de estos últimos años, podremos observar si el derecho al olvido está transformándose en un nuevo derecho subjetivo y autónomo, estrechamente vinculado a la dignidad de la persona, derivado de los derechos de la personalidad y la autodeterminación informativa, así como apuntar los retos inminentes a los que se enfrentará y plantear posibles soluciones de cara al perfeccionamiento de su regulación en el ámbito del Derecho Constitucional español y europeo, perfilando así su verdadera naturaleza.

\section{LA COMPLEJIDAD DEL ENTRAMADO NORMATIVO RELATIVO AL DERECHO AL OLVIDO}

\subsection{Consagración de la base normativa en el seno del Consejo de Europa}

Aunque, en el seno del Consejo de Europa, en lo relativo al derecho vinculante, el Convenio Europeo de Derechos Humanos (en adelante "CEDH”) no reconoce ex-

30 M. ÁLVAREZ CANO, Derecho al olvido en Internet: el nuevo paradigma de la privacidad en la era digital, Reus, Madrid, 2015, p. 27.

31 A. TOURIÑO, El derecho al olvido y a la intimidad, cit., p. 45.

32 L. COTINO HUESO, "La STJUE del caso google vs AGPD de 2014. Algunos "olvidos" $\mathrm{y}$ otras tendencias negativas respecto de las libertades informativas en internet", ponencia en Seminari interdepartamental de la Facultat de Dret de València.

33 R. MARTÍNEZ MARTÍNEZ, “QQuién debería olvidarnos...”, cit., y N.N. GOMES DE ANDRADE, "El olvido: El derecho a ser diferente... de uno mismo Una reconsideración del derecho a ser olvidado", En: VII Congreso Internacional Internet, Derecho y Política. Neutralidad de la red y otros retos para el futuro de Internet [monográfico en línea], IDP. Revista de Internet, Derecho y Política, n.o 13, 2012, pp. 67-83.

34 J.C. SUÁREZ VILLEGAS, "El derecho al olvido, base de tutela de la intimidad. Gestión de los datos personales en la Red", TELOS (Febrero - mayo), 2014, p. 2. 
plícitamente un derecho al olvido digital, sí que consagra, en su artículo 8, el derecho al respeto a la vida privada y familiar ${ }^{35}$. No obstante, podemos afirmar que la noción de "vida privada" engloba una realidad y un contenido amplio y variado, y que abarca prácticamente todos los acontecimientos vitales de una persona así como todos los actos que expresan un comportamiento o una conducta personal. Como derecho humano, el derecho a la vida privada tiene una protección reforzada, y por ello mismo, como apreciaremos más adelante, el Tribunal Europeo de Derechos Humanos ("TEDH", en adelante) ha ido perfilando y aclarando el contenido del derecho a la vida privada, en general, y recientemente manifestado, de manera concreta en Internet, a través de su vertiente en el derecho a la protección de datos e intimidad en la Web.

Si bien es cierto que la materialización inicial del derecho a la protección de datos, como precursor del derecho al olvido digital, así como uno de los orígenes del mismo, se manifestó en la década de los años setenta, en Estados europeos concre$\operatorname{tos}^{36}$, el gran desarrollo normativo a nivel internacional en materia de protección de la intimidad y la vida privada en el mundo digital se dio con la adopción de las Directrices de la Organización para la Cooperación y el Desarrollo Económico (en adelante "OCDE") ${ }^{37}$ en 1980 y el Convenio n ${ }^{\circ} 108$ sobre la protección de las personas con respecto al tratamiento automatizado de datos de carácter personal (en adelante, "Convenio 108") del Consejo de Europa (en adelante, “CdE"), en 1981 ${ }^{38}$. Aunque las Directrices de la OCDE carecían de carácter obligatorio, el Convenio 108, se presenta como norma fundamental de obligada referencia precisamente porque es el primer texto a nivel europeo regulador de la materia ${ }^{39}$. De hecho, se puede calificar de transcendental no sólo por ser el único instrumento internacional legalmente vinculante en materia de protección de datos, sino por constituir un paso clave en el desarrollo del Derecho material, pues ya entonces se aludía a la relación entre el tra-

35 Así, establece que: "toda persona tiene derecho al respeto de su vida privada y familiar [...] no podrá haber injerencia de la autoridad pública en el ejercicio de este derecho sino en tanto en cuanto esta injerencia esté prevista por la ley y constituya una medida que, en una sociedad democrática, sea necesaria para la seguridad nacional, la seguridad pública, el bienestar económico del pais, la defensa del orden y la prevención de las infracciones penales, la protección de la salud o de la moral, o la protección de los derechos y las libertades de los demás".

36 Con la adopción de dos vertientes distintas de regulación: una legislación ad hoc y a través de disposiciones de rango constitucional relativas al tratamiento automatizado de datos de carácter personal (entre los que se pueden destacar el caso alemán, sueco, francés, austriaco, portugués y español). Para un análisis exhaustivo de esta cuestión, véase G. GONZÁLEZ FUSTER, The Emergence of Personal Data Protection as a Fundamental Right of the EU, Springer, Bruselas, 2015, p. 55-71.

37 Directrices sobre la protección de la privacidad y los flujos transfronterizos de datos personales de la Organización para la Cooperación y el Desarrollo Económico (OCDE). Disponible en: http://inicio.ifai.org.mx/Estudios/OCDE-Directrices-sobre-protecci-oo-n-de-privacidad-Trad. $p d f . p d f$

El Convenio n ${ }^{\circ} 108$ del Consejo de Europa, de 28 de enero de 1981, para la protección de las personas con respecto al tratamiento automatizado de datos de carácter personal. Disponible en: http://www.coe.int/en/web/conventions/full-list/-conventions/rms/0900001680078b37

39 M.M. SERRANO PÉREZ, El derecho fundamental a la protección de datos. Derecho español y comparado, Thomson Civitas, Madrid, 2003, p. 89. 
tamiento de datos personales y conceptos constitucionalmente protegidos, vinculando la vida privada, consagrada en el artículo 8 del CEDH, con la intimidad y con la protección de datos de carácter personal ${ }^{40}$. Más concretamente, en su artículo 8 , hace referencia a una serie de garantías complementarias para el afectado, entre las que incluye la posibilidad de rectificar o borrar datos de carácter personal, cuando estos se hayan tratado de manera ilícita ${ }^{41}$. He aquí una de las primeras manifestaciones, en el seno del Consejo de Europa, del ahora archiconocido derecho al olvido digital, conectándolo con el derecho humano a la vida privada.

En lo relativo al derecho programático actual, cabe hacer alusión a varios instrumentos relevantes, entre ellos la Guía de derechos humanos para los usuarios de Internet, sobre todo a su apartado dedicado a la privacidad ${ }^{42}$, la actual Estrategia 2016-2019 del CdE sobre democracia, derechos humanos y el estado de derecho en el mundo digital ${ }^{43}$, la Recomendación sobre la protección de los derechos humanos en relación con los servicios de redes sociales ${ }^{44}$, la Recomendación sobre la protección de los derechos humanos y la privacidad de los usuarios con respecto a los motores de búsqueda ${ }^{45}$, la Recomendación sobre la protección de las personas en lo que respecta al tratamiento automatizado de datos personales en el contexto de la elaboración de perfiles ${ }^{46}$, así como la Recomendación de 1 de abril de 2015 (que hace alusión indirecta al derecho al olvido, en el ámbito laboral $)^{47}$. Del mismo modo, la Asamblea Parlamentaria del Consejo de Europa ("APCdE", en adelante) asume, entre otras muchas, la tarea de asegurar la protección y el respeto de los derechos

40 Y así se estableció en su preámbulo. Versión española publicada en el BOE núm. 274, de 15 de noviembre de 1985: "[...] ]es deseable ampliar la protección de los derechos [...]concretamente el derecho al respeto de la vida privada, teniendo en cuenta la intensificación deja circulación a través de las fronteras de los datos de carácter personal que son objeto de tratamientos automatizados [...]".

41 Vid. Artículo 8, apartado c, del Convenio 108.

42 Human Rights guide for internet users. Disponible en: http://www.coe.int/en/web/internet-users-rights/privacy-and-data-protection. Donde se hace referencia a la necesidad de proteger el libre desarrollo de la personalidad.

43 Internet Governance - Council of Europe Strategy 2016-2019 Democracy, human rights and the rule of law in the digital world.

44 Recommendation CM/Rec(2012)4 of the Committee of Ministers to member States on the protection of human rights with regard to social networking services, adoptada el 4 de abril de 2012 .

45 Recommendation CM/Rec(2012)3 of the Committee of Ministers to member States on the protection of human rights with regard to search engines, refers to a number of measures that providers can take to protect their users' privacy, adoptada el 4 de abril de 2012.

46 Recommendation CM/Rec(2010)13 of the Committee of Ministers to member States on the protection of individuals with regard to automatic processing of personal data in the context of profiling, adoptada el 23 de noviembre de 2010.

47 The Committee of Ministers adopts the Recommendation CM/Rec(2015)5 on the processing of personal data in the context of employment, adoptada el 1 de abril de 2015. Esta especifica que los datos personales presentados como apoyo de una solicitud de empleo o a efectos de una investigación interna corporativa deben suprimirse en determinadas circunstancias, de ofício o a instancia de parte. 
humanos y el Estado de Derecho en Internet a través de la formulación y aplicación de normas y políticas comunes en el ámbito de la gobernanza digital (Internet Governance). A modo de ejemplo, cabe mencionar el reciente y todavía proyecto de recomendación de 24 de enero de 2017 en el que se aboga por la creación de una suerte de Defensor del Pueblo Digital o Defensor del Internauta ${ }^{48}$ todo lo cual podría suponer una mejor protección y una garantía efectiva de los derechos más fundamentales de las personas en el mundo virtual a nivel del CdE.

\subsection{Reforzamiento de la base normativa en el seno de la Unión Europea}

La adopción del Convenio 108 y su actual reforma se puede calificar, sin lugar a dudas, como uno de los grandes hitos en el desarrollo de normas sobre la protección de la intimidad y la vida privada en la era digital ${ }^{49} \mathrm{y}$ sus principios han servido como base para toda la legislación europea y nacional posterior, tanto en materia de protección de datos, como en su vertiente específica plasmada como la garantía del derecho al olvido. Así, aunque no existe una mención explícita a un derecho al olvido digital, dado que este parte del derecho a la protección de datos, cabe apuntar que goza de un reconocimiento y regulación en la Unión Europea que se refleja tanto en el derecho originario como en el derivado. Con respecto al derecho originario, cabe centrarse en el Tratado de Funcionamiento de la Unión Europea, que incluye, en su artículo 16, una nueva competencia general (legislativa específica) de la UE para legislar en materia de protección de datos. Asimismo, el catálogo de derechos que constituye la Carta de Derechos Fundamentales de la Unión Europea ("CDFUE", en adelante), desde el Tratado de Lisboa un documento jurídicamente vinculante y con el mismo valor que los demás tratados constitutivos, que dota de mayor visibilidad a los derechos fundamentales a través de la consagración de un texto dogmático ${ }^{50}$, reconoce y garantiza una serie de derechos directamente vinculados al derecho al olvido digital. De este modo, la CDFUE no solo garantiza el respeto a la vida privada y familiar en su artículo 7 , derechos indirectamente vinculados a la intimidad y privacidad en el ámbito informático, sino que también establece el derecho a la protección de datos en su artículo 8 , gozando este de su propio precepto, consagrando, de manera explícita, su naturaleza de derecho fundamental y elevando, de manera significativa, su protección, y la de los derechos que surjan de él, en el ordenamiento jurídico europeo ${ }^{51}$.

48 El proyecto de recomendación lo califica como Internet Ombudsman con el cometido de, entre otras cosas, evaluar la naturaleza legal o ilegal de los contenidos en la Web y de establecer mecanismos de cooperación transfronteriza y reconocimiento de resoluciones nacionales, sobre la rectificación o supresión de datos, entre otras.

49 A. GALETTA y P. DE HERT, "A European perspective on data protection and access rights”, en C. Norris y X. L'hoiry (Coords.), Deliverable D5: Exercising democratic rights under surveillance regimes, p. 8.

50 L. JIMENA QUESADA, "La Carta de Derechos Fundamentales de la UE: rango legal y contenidos sustantivos", Cuadernos europeos de Deusto, $n^{\circ}$ 40, 2009, p. 63.

51 La coexistencia de ambos preceptos puede justificarse como conciliación entre los dos grandes enfoques de regulación de dicho derecho por los Estados Miembros (compromiso entre aquellos ordenamientos y tradiciones jurídicas que reconocían el derecho a la protección de datos 
Como se ha podido observar, hasta hace bien poco el derecho al olvido digital no estaba explícitamente mencionado en ningún instrumento normativo en el seno de la Unión Europea. A pesar de tener bases jurídicas en el derecho originario o primario, también encontramos normativa, de carácter derivado, que regula el derecho a la protección de datos, y como veremos, de manera directa e indirecta, un derecho al olvido digital. El instrumento jurídico europeo principal en materia de protección de datos hasta 2016 fue la Directiva 95/46/CE ${ }^{52}$ (Directiva de protección de datos) ${ }^{53}$. Su calificación de principal ${ }^{54}$ viene dada por ser el primer instrumento de la CDFUE y de las modificaciones devenidas del Tratado de Lisboa, que reconoció el derecho a la protección de datos a través de la noción de proteger la intimidad y privacidad en el tratamiento de los datos personales ${ }^{55}$. La Directiva de protección de datos establece, a lo largo de su articulado, la necesidad de dotar a los usuarios de unos derechos y la necesidad de crear unas obligaciones para los responsables del tratamiento de datos, en aras de proteger y garantizar los derechos fundamentales de las personas en la Red Internet, todo ello a través de derechos y deberes de rectificación, oposición y supresión del tratamiento de datos en determinadas circunstancias ${ }^{56}$. Estas disposiciones, junto con el hecho de que la Directiva se redactara con el objetivo principal de proteger los derechos y libertades fundamentales de los individuos, tales como su privacidad e intimidad en lo relativo al tratamiento de sus datos, se deben interpretar más bien como el primer paso y el punto de partida del reconocimiento del que luego sería el derecho al olvido digital. El recientemente adoptado Reglamento General de Protección de Datos (RGPD) ${ }^{57}$ deroga y sustituye a la Directiva 95/46/CE ${ }^{58}$, es-

como intrínsecamente ligado a la privacidad e intimidad, y aquellos que reconocían el derecho a la protección de datos como un derecho fundamental independiente y autónomo.

52 Directiva 95/46/CE del Parlamento Europeo y del Consejo, de 24 de octubre de 1995, relativa a la protección de las personas físicas en lo que respecta al tratamiento de datos personales y a la libre circulación de estos datos. Disponible en: http://eur-lex.europa.eu/LexUriServ/LexUriServ.do? uri $=$ CELEX:31995L0046:es:HTML

53 Como instrumento adoptado para regular la armonización de protección de los datos en el ámbito de la libre circulación en el mercado interior, que incluía también la libre circulación de datos.

${ }^{54}$ Algunos incluso la han calificado de hito en la historia de la protección de los datos personales en la UE. Vid., por ejemplo, A. RALLO LOMBARTE, "Hacia un nuevo sistema europeo de protección de datos: las claves de la reforma", Revista de Derecho Político (UNED), n.o 85 (septiembre-diciembre), 2012, p. 17 y ss.

55 Vid. artículo 1 de la Directiva que establece el objetivo de equiparar el nivel de protección de los derechos y libertades de las personas por lo que se refiere al tratamiento de datos personales en todos los Estados miembros.

56 Vid. artículos 12(b), 12 (c) y 14(b) de la Directiva, entre otras.

57 Reglamento (UE) 2016/679 del Parlamento europeo y del Consejo de 27 de abril de 2016 relativo a la protección de las personas físicas en lo que respecta al tratamiento de datos personales y a la libre circulación de estos datos. Disponible en: http://eur-lex.europa.eu/legalcontent/ES/TXT/PDF/? uri $=$ CELEX:32016R0679\&from $=E N$

58 En este sentido, cabe recordar que el RGPD tiene la particularidad de que entró en vigor el 24 de mayo de 2016 pero se aplicará directamente en los Estados miembros, a partir del 25 de mayo de 2018. 
tableciendo un verdadero y único conjunto paneuropeo relativo a la protección de la intimidad en un mundo digitalizado, siendo evidente la necesidad de una modernización en el aparato jurídico relativo a la protección de datos ${ }^{59}$. Este nuevo marco jurídico ha comportado una revisión global del sistema europeo de protección de datos, tanto en el ámbito formal como sustantivo, dado que se decide regular la reforma mediante un Reglamento y se abordan nuevas retos y problemas no debidamente regulados con anterioridad ${ }^{60}$. El RGPD supone, por lo tanto, un refuerzo del derecho a la protección de datos como pilar básico de las garantías y libertades en una Europa digitalizada y pretende alcanzar una verdadera armonización, en todo el territorio de la UE, en materia de protección de datos, mediante el uso de una norma única y de aplicación directa en todos los Estados Miembros. Así pues, y debido a que la protección conferida al derecho al olvido digital gira alrededor de la noción del derecho fundamental a la protección de datos, se analizará de manera exhaustiva la nueva normativa vigente, relativa a la regulación en cuanto se refiere a la consagración de este nuevo derecho emergente de la era digital.

Si bien es cierto que el RGPD refleja en gran medida los principios ya establecidos en la Directiva anterior, una de las novedades más relevantes del mismo se encuentra precisamente en la consagración específica y el refuerzo de ciertos derechos, que permiten un mayor control sobre el uso de los datos de carácter personal, entre ellos el archiconocido "derecho al olvido digital". En este sentido, cabe hacer mención del Considerando 65 del RGPD ${ }^{61}$, así como el Considerando 66 del RGPD ${ }^{62}$, con alusión explícita a la finalidad del derecho al olvido digital, bautizándolo como tal. Este derecho a obtener la eliminación de datos personales se reconoce y se regula expresamente en el artículo 17 bajo el título Derecho de supresión ("el derecho al olvido»). Hay autores que incluso consideran que es mejor hablar de "suprimir" que de "olvidar": unos advierten que todo derecho implica una correlativa obligación y que la obligación a olvidar es un imposible ${ }^{63}$ y otros recuerdan que este derecho no

59 la Directiva de protección de datos se adoptó en un momento en el que el desarrollo de la Web estaba en una fase incipiente y los retos planteados en el entorno digital actual requieren de normas actualizadas, uniformes y eficaces para garantizar los derechos más fundamentales en riesgo, no previstos en el siglo anterior, y nos atreveríamos a decir no previstos en el año anterior.

60 A. RALLO LOMBARTE, "Hacia un nuevo sistema europeo de protección de datos...", cit., p. 16. En efecto, la falta de armonización de legislaciones hasta la fecha, así como la falta de garantías jurídicas para el ejercicio efectivo del derecho a la protección de los datos de carácter personal han abocado a la necesidad de dar un paso hacia adelante.

${ }_{61}$ Cuando afirma que "los interesados deben tener derecho a que se rectifiquen los datos personales que le conciernen y un «derecho al olvido»[...] deben tener derecho a que sus datos personales se supriman y dejen de tratarse [...]".

62 Que apunta que "a fin de reforzar el «derecho al olvido» en el entorno en línea, el derecho de supresión debe ampliarse de tal forma que el responsable del tratamiento que haya hecho públicos datos personales esté obligado a indicar a los responsables del tratamiento que estén tratando tales datos personales que supriman todo enlace a ellos, o las copias o réplicas de tales datos".

63 R. PAZOS CASTRO, El mal llamado “derecho al olvido" en la era de Internet, Boletín del Ministerio de Justicia (Estudio doctrinal), n.o 2138, 2015, p. 6. 
está sujeto al paso del tiempo (puede ser aplicado tan pronto como se procesen los datos, sin necesidad de que transcurra un lapso temporal) ${ }^{64}$. No obstante, se puede apreciar el peso e influencia que llegó a tener el caso Google Spain, SL, que más adelante analizaremos, para el legislador europeo, pues dedica y titula una disposición al "derecho al olvido" digital. El artículo 17 RGPD establece la existencia de un derecho y un deber a la supresión de datos personales ${ }^{65}$. Sentado lo cual, el propio RGPD deja claro que el derecho al olvido digital no es absoluto ni automático, pues existen unas excepciones para su aplicación ${ }^{66}$. Por lo tanto, llegamos a dos conclusiones principales. En primer lugar, el hecho de que exista una protección reforzada para los usuarios a través de un mayor control sobre sus propios datos personales hace que la adopción del nuevo RGPD sea un paso importante hacia la reafirmación de que la dignidad y libertad personal deben tener garantías específicas a través de una autodeterminación informativa que permita a los usuarios colocarse en igualdad de condiciones para enfrentarse a los daños potenciales que brinda la hipermnesia del mundo virtual y el uso que de sus datos se haga en él. Si hacemos una lectura atenta del RGPD, observamos que el derecho al olvido que consagra el artículo 17 supone la facultad o el poder de cada individuo de decidir sobre la facilidad o imposibilidad de acceso de sus propios datos personales. Así pues, el derecho al olvido se enmarca dentro de la dignidad y libertad personal de cada individuo y el respeto a su vida privada e intimidad en el ámbito digital. Y, en segundo lugar, el RGPD, como la jurisprudencia a todos los niveles y la doctrina no se cansan de apuntar, nos recuerda que ningún derecho es absoluto y que debe de existir un equilibrio entre derechos e intereses, siendo las llamadas libertades informativas ${ }^{67}$ (libertad de expresión, derecho y deber de información, principalmente) un contrapeso, que se vehicula mediante excepciones a la regla general.

En lo que se refiere al derecho a la protección de datos de carácter personal, en general, y al derecho al olvido digital, en particular, podríamos destacar, entre otros

${ }^{64}$ S. CARNEROLI, Le droit à l'oubli. Du devoir de mémoire au droit à l'oubli, Larcier, Bruselas, 2016, p. 72.

${ }_{65}$ A grandes rasgos, cuando estos ya no sean necesarios para los fines con los que fueron recogidos o tratados, cuando el interesado retire su consentimiento, cuando el interesado se oponga al tratamiento y no existan motivos fundados para continuar con dicho tratamiento, cuando los datos hayan sido tratados ilícitamente, cuando sea necesario para el cumplimiento de una obligación legal establecida en el Derecho de la UE o nacional y cuando se hayan obtenido mediante una oferta de servicios electrónicos.

66 Entre ellas el ejercicio de la libertad de expresión, el cumplimiento de una obligación legal o misión realizada por motivos de interés público o salud pública, con fines de archivo, de investigación científica, histórica, con fines estadísticos, y en caso de ser necesario para la formulación, el ejercicio o la defensa de reclamaciones.

${ }^{67}$ Un análisis interesante del enfrentamiento entre el derecho al olvido y las libertades informativas se puede encontrar en L. COTINO HUESO, "La colisión del derecho a la protección de datos personales y las libertades informativas en la red: pautas generales y particulares de solución", en L. Cotino Hueso (ed.), Libertades de expresión e información en Internet y las redes sociales: ejercicio, amenazas y garantías, Publicaciones de la Universidad de Valencia, Valencia, 2011, p. 386 a 401. 
muchos instrumentos recientes del soft governance ${ }^{68}$ de la UE, la Declaración del Grupo de Trabajo del artículo 29 sobre el Plan de Acción de 2016 relativo a la aplicación del $R G P D^{69}$ y la Comunicación sobre el intercambio y protección de datos de carácter personal en un mundo globalizado ${ }^{70}$.

\subsection{Desarrollos y adaptaciones normativas en España}

Cabe recordar que el ordenamiento jurídico español, a día de hoy, todavía no cuenta con una base jurídica específica que consagre y regule un derecho al olvido digital. Resulta necesario apuntar la existencia de un reconocimiento informal del derecho al olvido digital a través del papel pionero de la Agencia Española de Protección de Datos y sus resoluciones ${ }^{71}$. No obstante, el fundamento del mismo encuentra su base en el derecho fundamental a la intimidad personal y en el derecho fundamental a la protección de datos, reconocidos en el artículo 18 (apartados 1 y 4, respectivamente) de la Constitución Española. Nuestro propio Tribunal Constitucional ha entendido que este precepto reconoce a las personas el poder de control y disposición sobre sus datos personales a través de una serie de facultades ${ }^{72}$, entre las que, argumentamos, se podría anclar el derecho al olvido digital. Sin embargo, debido al ritmo acelerado de la revolución tecnológica y digital, así como de las respuestas que se están dando a nivel europeo, encontramos nuevas afectaciones al diseño constitucional español de los derechos fundamentales, lo que indudablemente requiere de nuevas reformas jurídicas. Por ello, en nuestra opinión, el derecho al olvido también se fundamenta en la dignidad humana y en el libre desarrollo de la personalidad, consagrados en el artículo 10 de la Constitución española, pues la posibilidad y la finalidad del derecho al olvido, o de los tradicionales derechos de oposición y cancelación, responden a cuestiones relativas a nociones de dignidad y libertad personal.

La vigente Ley Orgánica 15/1999, de 13 de diciembre, de Protección de Datos de Carácter Personal ("LOPD", en adelante), y el Real Decreto 1720/2007, de 21 de diciembre, por el que se aprueba el Reglamento de desarrollo de la misma ("RDLOPD" en adelante), aunque no reconocen expresamente un derecho al olvido digital, sí que reflejan facultades de control sobre los datos de carácter personal, regulando los famo-

${ }_{68}$ Que han hecho, en general, especial hincapié en aumentar el control de los ciudadanos sobre sus datos, procurando dotarles de un derecho efectivo al olvido digital, así como en mejorar los medios que permiten el ejercicio de los derechos en juego.

${ }^{69}$ Vid. 442/16/EN WP 236. Statement on the 2016 action plan for the implementation of the General Data Protection Regulation (por su título en inglés).

${ }^{70}$ Vid. COM(2017) 7 final. Comunicación de la Comisión al Parlamento Europeo y al Consejo, "Exchanging and Protecting Personal Data in a Globalised World" (por su título en inglés) en la que se aboga por un "proteccionismo digital" y se recuerda que los derechos de las personas en el mundo digital, y aquí se podría incluir desde la intimidad informática (o privacidad) hasta la dignidad humana, no son mercancías con las que se pueda comercializar o negociar.

71 Así lo señala P. SIMÓN CASTELLANO, "El derecho al olvido en el universo 2.0", Textos universitaris de biblioteconomia i documentació -Universitat de Barcelona, n.o 28, 2012.

72 Vid. por todas, la célebre STC 290/2000 de 30 de noviembre, Fundamento Jurídico 7. 
sos derechos ARCO (acceso, rectificación, cancelación y oposición). Centrándonos en los dos últimos, ya que podrían constituir el punto de partida del derecho al olvido digital $^{73}$, cabe apuntar que el derecho de cancelación está regulado principalmente en el artículo 16 de la LOPD y en los artículos 31.2, 32 y 33 de la RDLOPD, como facultad subjetiva que permite la anulación de datos que han dejado de ser útiles para la finalidad para la que fueron recogidos o $\operatorname{tratados}^{74}$, mientras que el derecho de oposición se regula en los artículos 5, 6, 17, 18, 28 y 30 de la LOPD y en los artículos 23 a 26 y 34 a 36 del RDLOPD, como la facultad subjetiva para objetar al tratamiento de datos personales en determinados supuestos ${ }^{75}$. Tal y como ha apuntado parte de la doctrina académica, es necesario ofrecer garantías mediante el reconocimiento de nuevos derechos que garanticen un equilibrio entre la naturaleza abierta de Internet y la protección de la 'privacidad'76. Por esto mismo, y en aras de cumplir con la nueva normativa europea, España prepara la reforma de la LOPD. El trabajo conjunto de la AEPD y la sección de Derecho Público de la Comisión General de Codificación del Ministerio de Justicia ha cristalizado en una primera versión del anteproyecto de ley de modificación de la LOPD. En cuanto al derecho al olvido digital se refiere, el anteproyecto ha reconocido, de manera expresa, un derecho de supresión (artículo 25) remitiendo su ejercicio a lo establecido por el supracitado artículo 17 RGPD. Además, cabe destacar la novedosa regulación del derecho al olvido en el caso de las personas fallecidas (artículo 3), permitiendo que los herederos puedan solicitar la supresión de datos personales, extendiendo el ámbito del derecho al olvido y por ende permitiendo un mayor control de los datos de carácter personal tras la muerte.

A continuación, se pretende hacer un examen tripartito de la jurisprudencia emanada en el ámbito del CdE, de la UE y de España, en relación con la consagración de un derecho al olvido digital. En el caso de las dos primeras, no sólo por la necesidad de conciliar la actividad de las dos organizaciones del Viejo Continente en el marco del sistema europeo de derechos fundamentales, máxime tras la vigencia de la CDFUE como parte del Derecho primario de la UE y su necesaria convivencia con el nivel de protección del CEDH, sino asimismo, porque a esa colaboración estrecha entre ambas organizaciones se apelaba ya en los Tratados constitutivos de las entonces denominadas Comunidades Europeas.

73 Así lo viene observando P. SIMÓN CASTELLANO, El reconocimiento del derecho, cit., p. 195.

74 La propia Agencia Española de Protección de Datos (“AEPD”, en adelante) lo define, en su canal para el ciudadano, como "el derecho de cancelación permite que se supriman los datos que resulten ser inadecuados o excesivos sin perjuicio del deber de bloqueo recogido en la LOPD". Disponible en: http://www.agpd.es/portalwebAGPD/CanalDelCiudadano/derechos/principales_ derchos/index-ides-idphp.php

75 La AEPD los define, en su canal para el ciudadano, como "el derecho del afectado a que no se lleve a cabo el tratamiento de sus datos de carácter personal o se cese en el mismo". Disponible en: http://www.agpd.es/portalwebAGPD/CanalDelCiudadano/derechos/principales_derchos/ index-ides-idphp.php

76 A. RALLO LOMBARTE, "A partir de la protección de datos. El derecho al olvido y su protección”, TELOS, n.o 85 (Octubre - Diciembre), 2010, p. 5. 


\section{AVANCES JURISPRUDENCIALES EN MATERIA DEL DERECHO AL OLVIDO}

\subsection{Líneas desarrolladas por el TEDH y el CEDS}

A pesar de no existir un reconocimiento explícito en la normativa vinculante o programática en el seno del CdE, de un derecho al olvido digital, ni tampoco de un derecho fundamental a la protección de datos, resulta, no obstante, insoslayable introducir una breve referencia a la jurisprudencia del TEDH, en tanto en cuanto sí que ha interpretado el artículo 8 del CEDH en la segunda dirección. A este respecto, debe señalarse que la jurisprudencia del TEDH, sobre el desarrollo del derecho a la protección de datos de carácter personal, se ha basado en el derecho al "respeto de la vida privada" (art. $8 \mathrm{CEDH}$ ), libre de toda injerencia, salvo cuando, como dispone su apartado 2, dicha injerencia esté legalmente establecida o sea necesaria en función de un interés público. Así pues, se examinarán las sentencias más destacadas y originarias de los derechos y principios en los que se basa, a día de hoy, el reconocimiento de un derecho humano a la protección de datos de carácter personal, así como las sentencias más recientes y relevantes, que van tendiendo a un reconocimiento indirecto del derecho al olvido digital en el seno del Consejo de Europa, tanto por parte del TEDH, como del Comité Europeo de Derechos Sociales ("CEDS", en adelante).

Las bases del derecho en el olvido digital son, en primer lugar, el derecho a la intimidad personal y familiar (lo que el CEDH llama "vida privada y familiar") y, en segundo lugar, el derecho a la protección de datos personales. Acerca de estos derechos, se debe mencionar que el TEDH ha consagrado el derecho a la protección de datos de carácter personal como un componente del derecho a la vida privada y familiar (consagrado en el artículo 8 del CEDH), en asuntos como Gaskin c. Reino Unido ${ }^{77}, Z$ c. Finlandia ${ }^{78}$ y L.L. C. Francia ${ }^{79}$. La jurisprudencia del TEDH viene a consolidarse en otros asuntos como Leander c. Suecia ${ }^{80}$, Rotaru c. Ruma-

77 Sentencia de 7 de julio de 1989, Núm. de recurso 10454/83 que versaba sobre el acceso a los datos sobre la estancia de un individuo durante su infancia en un orfanato.

78 Sentencia de 26 de Febrero de 1997, Núm. de recurso 22009/93, que, en su apartado 95 establece: "[...] the protection of personal data, not least medical data, is of fundamental importance to a person's enjoyment of his or her right to respect for private and family life as guaranteed by Article 8 [...] It is crucial not only to respect the sense of privacy of a patient but also to preserve his or her confidence [...]". En otras palabras, que la protección de los datos de carácter personal, sobre todo, los médicos, reviste una importancia fundamental para el disfrute del derecho al respeto de la vida privada y familiar.

79 Sentencia de 10 de octubre de 2006, Núm. de recurso 7508/02, que, en su apartado 44 reitera que la protección de datos de carácter personal en general es principio fundamental en los ordenamientos jurídicos de los Estados miembros.

80 Sentencia de 26 de marzo de 1987, Núm. de recurso 9248/81. Este asunto versaba sobre la negativa de acceder a la información por la que se le negó a un señor (Sr. Leander) un puesto laboral, por considerarse un riesgo de seguridad sobre la base de dicha información almacenada en un registro estatal. El TEDH, aunque al final consideró que dicha injerencia estaba justificada, sí que señaló que el almacenamiento de información privada en un registro policial secreto como su puesta en libertad, 
nía ${ }^{81}$ y Amann c. Suiza ${ }^{82}$. Así, el TEDH, además de hacer suyo el concepto de "datos personales" que recogen el Convenio 108 del CoE y la Directiva sobre Protección de Datos de la UE, ha interpretado que serán objeto de protección tanto aquellos vinculados a la vida privada, como cualquier otro dato sobre la vida de una persona en tanto en cuanto afecte al desarrollo de su personalidad "porque es evidente que no todos los datos personales, es decir, todas las informaciones relativas a un individuo identificado o identificable, son igual de relevantes desde el punto de vista de la vida privada" ${ }^{83}$.

Además, el TEDH, en casos recientes como Brunet c. France ${ }^{84}$, ha reafirmado que la protección de datos de carácter personal es fundamental para el ejercicio efectivo del derecho al respeto a la vida privada ${ }^{85}$. Así, el TEDH prevé el derecho a la vida privada y familiar de manera muy amplia. Esto incluye, en primer lugar, una dimensión privada e íntima, el derecho al libre desarrollo de la personalidad y, en segundo lugar, una dimensión social, "el derecho a establecer y mantener relaciones con otros seres humanos y el mundo exterior" tal como apuntó en el caso Schlumpf c.

junto con la negativa a permitir la oportunidad de refutarlo, constituyen una injerencia en el derecho al respeto de la vida privada: "Both the storing and the release of such information, which were coupled with a refusal to allow Mr. Leander an opportunity to refute it, amounted to an interference with his right to respect for private life as guaranteed by Article 8 \& 1 (art. 8-1)" (apartado 48).

81 Sentencia de 4 de mayo de 2000, Núm. de recurso 28341/95. Este asunto trataba sobre la vulneración del derecho al respeto de la vida privada por el tratamiento y uso, por parte del Servicio de Inteligencia rumano, de información relativa a la condena de un abogado cuando era un joven estudiante durante el régimen comunista. El TEDH, por tanto, tenía que decidir si la retención y el uso de informaciones, algunas de las cuales eran inexactas, sobre las actividades pasadas del solicitante violaban el artículo 8 CEDH. En este caso, el TEDH concluyó que el almacenamiento de información relativa a la vida privada de un individuo, aunque plasmada en un registro secreto, y la divulgación la misma pueden entrar en el ámbito de aplicación art. 8.1 y que esto es todavía más cierto en lo que a datos concernientes a un pasado muy lejano: "Moreover, public information can fall within the scope of private life where it is systematically collected and stored in files held by the authorities. That is all the truer where such information concerns a person's distant past". A juicio del tribunal, cuando se recopila y almacena información de carácter personal, de manera sistemática, en un archivo estatal, como era el del servicio de inteligencia, entra en el ámbito de la "vida privada" a los efectos del artículo 8.1 del CEDH (apartados 43 y 44).

82 Sentencia de 16 de febrero de 2000, Núm. de recurso 27798/95. Aquí, el TEDH tenía que decidir si la creación y el almacenamiento de información sobre la base de escuchas telefónicas vulneraban los artículos 8 y $13 \mathrm{CEDH}$. El TEDH señaló que la noción de "vida privada" no se debe interpretar de manera restrictiva y concluyó que la recopilación y el uso de la información no habían sido «conformes a la ley», como exige el párrafo 2 del artículo 8 , debido a la ausencia en la legislación nacional pertinente de una protección adecuada contra la injerencia arbitraria.

83 M. ARENAS RAMIRO, El derecho fundamental a la protección de datos personales en Europa, Tirant lo Blanch, Valencia, 2006, p. 80.

84 Sentencia de 18 de septiembre de 2014, Núm. de recurso 21010/10.

85 Y que, por tanto la normativa interna debe de garantizar mecanismos para impedir la utilización ilícita de datos de carácter personal y "garantizar que estos datos son pertinentes y no excesivos en relación a la finalidad para la que fueron registrados, y que se conservan de forma que permita la identificación de las personas por un tiempo que no exceda el necesario a los fines para los que fueron registrados [...]". 
Suiza ${ }^{86}$. Además, según el TEDH en el caso Copland c. Reino Unido ${ }^{87}$, el almacenamiento de datos relativos al teléfono móvil o correo electrónico, sin el consentimiento de la persona, constituye una injerencia en el derecho a la vida privada (apartado 44), aclarando que tal derecho también incluye el control de la información personal. Esta faceta del derecho a la vida privada permite a un individuo elegir qué información personal se dará a conocer y con qué propósito. A estos efectos, el derecho al olvido digital, juega el papel crucial de permitir a una persona solicitar la supresión de información relativa a él o ella, para retornar a esa esfera interna y más íntima del derecho a la vida privada. No obstante, el TEDH todavía no ha tenido la oportunidad de pronunciarse en este sentido.Por otro lado, cabe traer a colación la jurisprudencia "clásica" y su evolución, referente al déficit de seguridad, la consiguiente lucha contra la criminalidad y la protección de la privacidad, que ha venido precisamente de la mano del derecho al respeto de la vida privada, del domicilio y de la correspondencia reconocido en el citado art. $8 \mathrm{CEDH}^{88}$. Así, en el caso Klass y otros c. Alemania ${ }^{89}$, aunque no declarara la violación del art. $8 \mathrm{CEDH}$, se perfilaron unos principios interesantes de ponderación entre la libertad y la seguridad: de un lado, el TEDH insistió especialmente en las cautelas que deben acompañar a las medidas de vigilancia, que deben estar previstas por la ley ${ }^{90}$; además, para superar el test de la necesidad en una sociedad democrática, debe haber garantías suficientes y efectivas contra los abusos, así como un control, en última instancia, por parte del poder judicial, o al menos por órganos independientes. En todo caso, las grandes líneas jurisprudenciales del TEDH sobre la protección de la privacidad y el déficit de seguridad habían sido delimitadas en el caso $S$. y Marper c. Reino Unido ${ }^{91}$. El TEDH determinó en primer término que, efectivamente, el simple hecho de memorizar datos relativos a la vida privada de un individuo constituye una injerencia en el sentido del art. $8 \mathrm{CEDH}$ (vid. apartado 67), siendo irrelevante que las informaciones memorizadas sean o no ulteriormente utilizadas. A tal efecto, el TEDH convino en que la conservación de los datos relativos a las huellas digitales y genéticas perseguía el fin legítimo de la detección y, por tanto, de la prevención de las infracciones penales, la conservación obedece al objetivo más amplio de contribuir a la identificación de futuros delincuentes. Ahora bien, en el caso de $S$. y Marper el TEDH llega a entender que la conservación de sus datos no era necesaria en una sociedad democrática, al no resultar proporcionada ni reflejar un justo equilibrio entre los intereses públicos y privados en conflicto, dado el carácter general, indiferenciado e ilimitado en el tiempo de ese poder de conservación en

86 Sentencia de 8 de enero de 2009, Núm. de recurso 29002/06, que, en su apartado 77, establece que: "La Cour rappelle que le droit au respect de la vie privée inclut le droit au développement personnel et le droit d'établir et d'entretenir des rapports avec d'autres êtres humains et le monde extérieur".

87 Sentencia de 3 de abril de 2007, Núm. de recurso 62617/00.

88 Para un análisis exhaustivo de esta cuestión, vid. B. TOMÁS MALLÉN, "Privacidad versus seguridad en el ámbito europeo", en A. Fayos Gardó y P. Conde Colmenero (coords.), Los derechos a la intimidad y a la privacidad en el siglo XXI, Dykinson, Madrid, pp. 215-241.

89 Sentencia de 6 de septiembre de 1978, Núm. de recurso 5029/71.

90 Y que ésta sea accesible, previsible y relativamente detallada.

91 Sentencia de 4 de diciembre de 2008, Núm. de recurso 30562/04 y 30566/04. 
manos de las autoridades británicas, llegando a la conclusión de violación del art. 8 $\mathrm{CEDH}^{92}$.

Hasta aquí, parecería que, en el seno del CdE, se avanza hacia el reconocimiento y salvaguardia de un derecho subjetivo y autónomo a la protección de datos de carácter personal, basado en sus vínculos con la intimidad y la vida privada, y no tanto a un reconocimiento jurisprudencial de un derecho al olvido digital. Por esto mismo, especialmente relevante resulta el caso Bărbulescu c. Rumania ${ }^{93}$ y los apuntes novedosos que hace sobre esta cuestión. A pesar de que el TEDH concluye que, en el caso concreto, no se vulnera el derecho a la intimidad del trabajador, sí que realiza un análisis exhaustivo de nociones tales como un derecho fundamental y autónomo a la protección de datos de carácter personal (vid. apartado 6), que el tratamiento de datos sensibles en el ámbito laboral goza de una protección especial (vid. apartados 7 y 11), así como la necesidad de garantizar una protección a la intimidad personal y libertad de expresión, y de regular exhaustivamente la cuestión, con respecto a comunicaciones electrónicas privadas en el contexto del trabajo (vid. apartado 9). Como se ha apuntado antes, aunque el TEDH consideró que en el caso concreto no se había vulnerado el derecho a la intimidad personal del trabajador ${ }^{94}$, esta sentencia sí que recogió un voto particular interesante, en el que se señalaba que el caso presentaba una excelente oportunidad para que el TEDH estableciera jurisprudencia en el área de la protección de la privacidad de las comunicaciones a través de Internet (vid. apartado 2 del voto particular). Precisamente, el Magistrado Pinto de Albuquerque sí que planta la semilla de lo que, en un futuro podría ser un derecho al olvido digital reconocido a nivel europeo, que no de la Unión Europea, cuando establece que los trabajadores tienen un derecho de eliminación o rectificación ${ }^{95}$. No obstante

92 Además, como han apuntado algunos autores, el TEDH no sólo clarifica los criterios de aplicabilidad del art. $8 \mathrm{CEDH}$ en relación al tratamiento de datos biométricos, sino que además, aclara y refuerza la relación entre el derecho a la vida privada y familiar y la protección de datos de carácter personal. En este sentido, para un análisis más exhaustivo, vid. G. GONZÁLEZ FUSTER, “TEDH - sentencia de 04.12.2008, y S. Marper c. Reino unido, 30562/04 y 30566/04 -artículo 8 CEDH - vida privada -injerencia en una sociedad democratica- los límites del tratamiento de datos biométricos de personas no condenadas", Revista de Derecho Comunitario Europeo, n.o 33, 2009, pp. 619-633.

93 Sentencia de 12 de enero de 2016, Núm. de recurso 61496/08. Este caso versaba sobre un empleado al que se le hizo un control de la actividad de una cuenta de correo laboral, y tras observar que se había usado para fines particulares, prohibido por la regulación interna de la empresa, fue despedido, lo que él alegaba constituía una vulneración de su derecho a la intimidad.

94 Así también lo ha establecido nuestro propio Tribunal Constitucional. Vid. Sentencia de 7 de octubre (Sala 1), núm. 2013/182887, conocida como sentencia del caso Alcaliber, (vid. Fundamento Jurídico 4).

95 De "datos [...] incorrectos o [...] incompletos [...] recopilados o procesados de manera incompatible con la política de la empresa. Los datos recopilados [...] Cuando ya no sea necesario, los datos [...] deberán eliminarse" (traducción propia de los apartados 12 y 13 del voto particular).Aquí, vemos que el juez parte de la profunda convicción de la necesaria protección de las libertades en Internet y considera que el ámbito protegido por la privacidad va más allá del contenido, incluyendo metadatos e injerencias que puedan obtenerse de datos especialmente protegidos. El reconocimiento de la importancia e estrecha relación entre la protección de la vida 
todo lo anterior, en virtud del procedimiento de reexamen (establecido en el artículo 43 del CEDH), la Gran Sala del TEDH tendrá la oportunidad de volver a resolver dicho cuestión.

Por último, y para completar el entramado jurídico del Consejo de Europa, vale la pena detallar la referencia a la Carta Social Europea de 1961 (revisada en 1996), puesto que el Comité Europeo de Derechos Sociales (CEDS) ha desarrollado una jurisprudencia que ha tenido presente asimismo la protección de la privacidad en tensión dialéctica con el déficit de seguridad, velando por la recogida de datos en condiciones de no discriminación, para evitar la estigmatización de categorías vulnerables de personas. En particular, es necesario mencionar la decisión de fondo de 25 de junio de 2010 sobre la Reclamación $n^{\circ}$ 58/2009 (Centre on Housing Rights and Evictions c. Italia). En lo que nos interesa, debe destacarse la violación del art. E en relación con el art. 16 (protección de la familia) ${ }^{96}$. Se trata realmente de una jurisprudencia nueva del CEDS que realza el principio de indivisibilidad y que es elaborada por analogía con respecto a la jurisprudencia del TEDH sobre el art. $8 \mathrm{CEDH}^{97}$. Así, el Comité entiende que el sistema de identificación no habría guardado el necesario respeto a las normas internacionales en la materia, entre ellas el Habeas Data ${ }^{98}$. Es interesante destacar la cita del apartado 120 de la decisión del Comité ${ }^{99}$ en tanto en cuanto reconoce la necesidad de restringir el margen de discrecionalidad nacional para "garantizar al individuo el disfrute efectivo de los derechos fundamentales o de orden 'intimo' que le son reconocidos".

Como se puede observar, en el seno del CdE estamos todavía lejos de llegar a un protección de la "privacidad" que permita reconocer un derecho autónomo a controlar y decidir sobre la supresión de los propios datos de carácter personal que se almacenan y se difunden, de manera irrestricta por la red; tampoco se ha planteado el caso concreto todavía. No obstante, recopilando los diferentes pronunciamientos del TEDH relativos al art. $8 \mathrm{CEDH}$, observamos que el TEDH lo ha interpretado, sin excepción alguna, en base a los principios y valores del Convenio 108 , y que por tanto, el sistema de protección de derechos humanos del gran continente europeo ha asentado las bases para avanzar hacia la protección de los

privada y la protección de datos personales, por parte del TEDH, ha sido paulatina pero contundente.

96 Tanto en la vertiente clásica de protección social y acceso a la vivienda como en la faceta civil, novedosa relativa a la protección frente a las injerencias injustificadas y discriminatorias en la vida familiar de las personas de etnia gitana, por el modo en que se había producido el censo e identificación de dichas personas en los campamentos (huellas digitales, almacenamiento de datos fotométricos e incluso en algunos casos una etiqueta identificativa para acceder al campamento).

97 L. JIMENA QUESADA, "Crónica de la Jurisprudencia del Comité Europeo de Derechos Sociales - 2010", Revista Europea de Derechos Fundamentales, n.o 16, 2014, p. 385-407.

98 Vid. apartado 119 de la decisión de 25 de junio de 2010.

99 "[...] si bien debe dejarse un margen de apreciación [...] será más restringido cuando el derecho en juego sea importante para garantizar al individuo el disfrute efectivo de los derechos fundamentales o de orden 'intimo' que le son reconocidos". 
datos personales vis-à-vis la vida privada, la intimidad personal, el libre desarrollo de la personalidad y la dignidad humana, y empieza a mostrar puntuales raíces que podrían germinar, en el futuro, en un reconocimiento explícito, de un derecho al olvido digital.

\subsection{Jurisprudencia específica del TJUE}

La labor pretoriana del Tribunal de Justicia de la Unión Europea ("TJUE", en adelante) en materia de derechos fundamentales es indudable. La jurisprudencia emergente del TJUE en lo que atañe a temas de protección de datos, y recientemente, con relación al derecho al olvido digital, ha sido motivo de gran desarrollo al reconocer no solo la protección de la vida privada e intimidad de las personas a la luz de la revolución tecnológico-digital, sino también, al reconocer nuevos derechos fundamentales. Antes de analizar en profundidad los desarrollos jursirpudenciales recientes, resulta pertinente, al menos, enumerar las primeras y más relevantes sentencias del TJUE en su perfeccionamiento del derecho fundamental a la protección de datos, como precursor del derecho al olvido digital. En esta línea, cabe aludir a la primera sentencia del TJUE indirectamente relacionada con la privacidad y la protección de datos: el Asunto Stauder ${ }^{100}$. Asimismo, cabe enumerar los siguientes casos planteados al TJUE: el Asunto Rechnungshof ${ }^{101}$ el Asunto Lindquist ${ }^{102}$, el Asunto Digital Rights Ireland Ltd ${ }^{103}$; en este último fue donde el TJUE aludió a un derecho fundamental a la protección de datos y a la vida priva$\mathrm{da}^{104}$ desarrollando parámetros constitucionales europeos cuando están en juego derechos fundamentales, aplicando un examen de proporcionalidad más estricto, con el fin de proteger, de manera efectiva y real, aquellos derechos reconocidos en el ordenamiento jurídico europeo. Además, por su peso específico, parece necesario destacar, aunque no directamente relacionado con el derecho al olvido digital,

100 Asunto C-29/69, Erich Stauder v City of Ulm, STJUE de 12 de noviembre de 1969 en el que sostuvo que la información identificable de los individuos no estaba justificada en este caso por ser innecesaria.

101 Asuntos acumulados C-465/00, C-138/01 y C-139/01, Rechnungshof v. Osterreichischer Rundfunk, STJUE de 20 de mayo de 2003. Vid. en especial su apartado 74.

102 Asunto C-101/01, Bodil Lindqvist, STJUE de 6 de noviembre de 2003. Vid. apartados 27-39.

103 Asuntos acumulados C-293/12 y C-594/12, Digital Rights Ireland Ltd v. Seitlinger y otros, STJUE de 8 de abril de 2014 donde el TJUE introdujo un examen de control estricto, a través de un test de proporcionalidad riguroso de los actos legislativos de la Unión que interfieren ponderadamente con los derechos a la vida privada y a la protección de datos de carácter personal, concluyendo que la mera obligación de conservación de datos de carácter personal era, por sí sola, una injerencia tanto al derecho a la vida privada como al derecho a la protección de datos, calificándolas de grandes, graves y generadoras de un sentimiento de que la vida privada es objeto de una vigilancia constante.

104 Del mismo modo, cabe mencionar el Asunto C-230/14, Weltimmo s.r.o. v. Nemzeti Adatvedelmi es Informacioszabadsag Hatosag, STJUE 1 de octubre de 2015. 
para comprender el modelo de garantista europeo con el respecto a la privacidad, el Asunto Schrems ${ }^{105}$ y Comisión v. Hungría ${ }^{106}$.

A continuación, se analizarán más detenidamente sentencias recientes que consideramos hitos jurisprudenciales, dado el reconocimiento formal de un derecho al olvido digital, que contribuyen a la consagración jurisprudencial de los dos derechos, por excelencia, en la era digital. En primer lugar, el Asunto Google Spain, $S L^{107}$ versaba sobre información indexada y almacenada en motores de búsqueda en Internet, el tratamiento y procesamiento de dichos datos y la interpretación de qué se considera controlador de datos. Esta sentencia se ocupó, en particular, de cuestiones relativas a los datos personales, la protección de las personas, el tratamiento de los datos y su almacenamiento en páginas web, así como la responsabilidad de los operadores de los motores de búsqueda y los derechos del interesado en relación con los artículos 7 y 8 de la Carta de Derechos Fundamentales de la UE y la Directiva 95/46/ CE. Según el TJUE, el tratamiento y procesamiento de datos incluye operaciones de descarga, pero también la exploración en Internet de manera automatizada, constante y sistemáticamente en búsqueda de información publicada que supone un motor de búsqueda se considera un controlador de datos de carácter personal, y dada la importancia de los motores de búsqueda en la actualidad, por tanto, el interés económico no puede justificar ni prevalecer sobre la injerencia en los derechos fundamentales del interesado ${ }^{108}$. Así pues, el motor de búsqueda debe borrar la información y los

105 Asunto C-362/14, Schrems v. DP Commissioner, STJUE de 6 de octubre de 2015 que versaba sobre la transferencia de datos personales a países terceros y su conformidad con el derecho fundamental a la protección de datos de carácter personal. Aquí, el TJUE aplica un test de necesidad estricta en aquellos casos en los que hay una injerencia y limitación en el ejercicio de los derechos fundamentales garantizados en los artículos 7 y 8 de la CDFUE, relativos a la vida privada y a la protección de datos. Hace esto a través de la provisión de un listado de condiciones específicas y estándares mínimos que debe reunir la legislación que interfiere con el derecho fundamental a la protección de datos o a la vida privada para que se considere dicha injerencia "estrictamente necesaria" o no. Asimismo, cabe resaltar el papel destacado que señala el propio TJUE que tiene en la interpretación y protección del derecho a la protección de datos de carácter personal, todo lo cual confirma la línea adoptada por el TJUE en el Asunto Google Spain, que analizaremos a continuación, marcando la distancia entre las garantías europeas y las estadounidenses en materia de protección de datos, pues en la UE se requiere una protección total, impidiendo que ciertas posibilidades que otorga Internet, como es la proliferación de los motores de búsqueda, el uso de las redes sociales o la ruptura de los límites espacio-temporales queden al margen de los estándares europeos de protección de los derechos fundamentales.

106 Asunto C-288/12, Comisión Europea v. Hungría, STJUE de 8 de abril de 2014 que versaba sobre la (falta) de independencia de la autoridad nacional supervisora de protección de datos. El TJUE recordaba que la creación de autoridades de control independientes a nivel nacional constituye un elemento esencial del respeto a la protección de las personas en lo que respecta al tratamiento de datos personales según la propia CDFUE (apartado 47) pues es su papel, como guardianas del derecho a la intimidad garantizar un justo equilibrio entre los intereses en juego, y por ende, deben de estar libres de toda fuerza e injerencia externa, ya sea directa o indirecta como puede ser la posibilidad de finalización prematura de su mandato (apartados 51, 58 y 60-61).

107 Asunto C-131/12, Google Spain, S.L., v. AEPD y Mario Costeja Gonzalez, STJUE de 13 de mayo de 2014.

108 Vid. apartado 81 de la STJUE de 13 de mayo de 2014: “[...] derechos de esa persona [...] prevalecen [...] sobre el mencionado interés de los internautas, no obstante, este equilibrio 
vínculos de la lista de resultados dado que el interesado en aras a garantizar una protección eficaz del derecho a la vida privada y del derecho a la protección de datos ${ }^{109}$, pues parece comprensible que un ciudadano pueda reaccionar ante la difusión y puesta a disposición de sus datos de carácter personal de forma irrestricta en un sistema tan universal como es Internet, no teniendo que resignarse ${ }^{110}$ a que su reputación, su identidad, su intimidad o su mismísima dignidad se vean comprometidas.

La doctrina que inspira esta decisión supone la consagración definitiva del derecho a ser olvidado en el mundo digital. Se ha reconocido a nivel europeo el derecho de los ciudadanos a solicitar que cualquier motor de búsqueda elimine la información que ellos consideran que es irrelevante para los demás y que podría perjudicar el propio derecho a la intimidad, al honor y a la propia imagen. No obstante, a pesar de la consagración jurisprudencial del "derecho al olvido", la decisión jurisprudencial ha dejado otras cuestiones relacionadas sin aclarar. Según parte de la doctrina, la sentencia adolece de suficiente claridad con respecto al ámbito material y territorial del "derecho al olvido", pues este se debe definir de una manera que sea proporcional a la capacidad real de aplicarlo en la práctica, si lo que se pretende es proteger, de manera efectiva, los derechos fundamentales ${ }^{111}$. Esta decisión también permitirá a los ciudadanos ejercer su derecho a reclamar ser olvidados en la web directamente ante la empresa del motor de búsqueda, incluso si la fuente original de la información no es completamente visible en Internet. En suma, esta decisión fue adoptada para resolver un conflicto entre los derechos fundamentales de las personas (derecho a la intimidad, vida privada y libre desarrollo de la personalidad) por una parte y la libertad de expresión, derecho a la información y principios como la promoción de intereses económico-sociales por otra, habida cuenta del papel vital que los motores de búsqueda de Internet juegan hoy en día en nuestras sociedades. Dichas herramientas digitales confieren una vasta información contenida en las listas de resultados, por lo que es necesario asegurarse de que los sujetos con tal poder garantizan la protección del derecho a la intimidad. De cara al enfoque basado en los derechos fundamentales y en la existencia de un derecho subjetivo al olvido digital que persigue este trabajo, es importante mencionar que el contenido de esta sentencia subraya que, a la luz de los artículos 7 y 8 de la CDFUE, un individuo tiene el derecho a solicitar que la información relativa a su persona, en una lista de resultados de un motor de búsqueda, no

puede depender, [...] de la naturaleza de la información de que se trate y del carácter sensible para la vida privada de la persona afectada y del interés del público [...]puede variar, [...] en función del papel que esta persona desempeñe en la vida pública"

109 Vid. apartado 99 de la STJUE de 13 de mayo de 2014: "[...] puede [...] solicitar que la información [...] ya no se ponga a disposición del público en general mediante su inclusión en tal lista de resultados, estos derechos prevalecen, en principio, no solo sobre el interés económico del gestor del motor de búsqueda, sino también sobre el interés de dicho público en acceder a la mencionada información en una búsqueda que verse sobre el nombre de esa persona [...]".

110 M. ARENAS RAMIRO, "Unforgettable: a propósito de la STJUE de 13 de mayo de 2014.Caso Conseteja (Google v. AEPD)", Teoría y Realidad Constitucional, n.o. 34, 2014, pp. 552-553.

111 C. KUNER, "The Court of Justice of the EU Judgment on Data Protection and Internet Search Engines”, LSE Law, Society and Economy Working Papers, n.o 3, 2015, p. 21. 
se incluya, o se elimine de esta lista de resultados. Cabe destacar el énfasis que le da el TJUE a la protección de datos de carácter personal y a la protección de derechos ligados a la personalidad, derechos ante los cuales se decanta inmediatamente, priorizándolos antes que a los derechos económicos de los operadores de los motores de búsqueda y que otros derechos fundamentales ${ }^{112}$.

Llegados a este punto, en el que nos percatamos de la estrecha relación entre el derecho fundamental a la protección de datos y el derecho a la vida privada y la garantía novedosa del "derecho al olvido digital", cabe analizar, de manera exhaustiva, la reciente sentencia, que junto con el Asunto Google Spain S.L, constituye un hito jurisprudencial del TJUE porque versa de manera cuasi estricta, sobre el derecho al olvido digital y porque presenta gran interés, pues delimita el alcance del mismo: el Asunto Manni ${ }^{113}$. El TJUE, en su sentencia de 9 de marzo de 2017 tenía que responder, esencialmente, a si las personas físicas, cuyos datos están grabados en un registro de sociedades, tienen un derecho al olvido. Es decir, un derecho a que los mismos sean suprimidos o anonimizados, o, al menos, a que se limite su publicidad, restringiendo la facultad de acceder a los mismos cuando haya transcurrido un determinado periodo de tiempo. El TJUE, en primer lugar, confirma que los datos de carácter personal que figuran en los registros de sociedades no pierden su naturaleza de "dato de carácter personal" por el mero hecho de formar parte del ámbito de una actividad profesional vehiculada a través de una persona jurídica (vid. apartado 34), y además confirma que el registro de sociedades implica un tratamiento de datos personales según lo dispuesto en el Derecho de la UE (vid. apartado 35) ${ }^{114}$. En segundo lugar, el TJUE recuerda la finalidad de las Directivas en cuestión, pues deben garantizar un nivel elevado de protección de derechos fundamentales, en particular el respeto de la vida privada en relación con

112 Y sin embargo, parte de la doctrina ha criticado y ha considerado la conclusión del TJUE discutible por otorgarle una prevalencia excesiva al derecho del afectado. En este sentido, vid. M. VILASAU SOLANA, "El caso Google Spain: la afirmación del buscador como responsable del tratamiento y el reconocimiento del derecho al olvido (análisis de la STJUE de 13 de mayo de 2014", Revista de Internet, Derecho y Política (IDP) de la UOC, n.o 18, 2014, p. 24. De hecho, tal como han apuntado algunos autores, "la fuerza expansiva del derecho al olvido ante los buscadores resulta extraordinaria y no conoce más límite que el que derive de la valoración del interés público de informaciones personales ponderado, sobre razones concretas, con la injerencia provocada en derechos fundamentales como la intimidad o la protección de datos personales" (A. RALLO LOMBARTE, "Caso Google vs. España. Sentencia del TJUE 13 de mayo de 2014: La garantía del derecho al olvido en internet”, Actualidad Jurídica Aranzadi, n.o 886, 2014, pp. 8-9).

113 Asunto C-398/15, Camera di Commercio, Industria, Artigianato e Agricoltura di Lecce v. Salvatore Manni, STJUE de 9 de marzo de 2017. El caso versaba sobre dudas suscitadas de cómo interpretar el Derecho de la UE con respecto a la Directiva de protección de los datos (95/46/ $\mathrm{CE})$ y la Directiva sobre la publicidad de los actos de las sociedades (68/151/CEE), y saber si estas se oponen a que cualquiera pueda acceder, sin límite temporal, a datos de personas físicas que figuren en un registro de personas jurídicas.

114 Esto podría plantear problemas en nuestro ordenamiento jurídico, pues el tratamiento de datos referidos a personas jurídicas o a los ficheros que se limiten a incorporar los datos de las personas físicas que presten sus servicios en estas están excluidos del ámbito de aplicación material de la LOPD y el RDLOPD. Vid. el actual artículo 2 de la RDLOPD, por ejemplo. 
el tratamiento de datos personales, solicitando, incluso "su rectificación o incluso oponerse a su tratamiento en determinadas circunstancias" (vid. apartado 38) y que cuando de un tratamiento de datos personales llevado a cabo por una autoridad pública se trata, este puede responder a causas legítimas tales como el respeto a una obligación legal o la realización de un interés público, y que así se ha pronunciado el propio TJUE ${ }^{115}$ (vid. apartados 41 y 42). Así, el TJUE señala que para determinar si existe una obligación y derecho a solicitar la supresión o bloqueo de datos personales contenidos en un registro de sociedades, depende de la finalidad de la inscripción y su inclusión (vid. apartado 48). En el caso de la Directiva sobre la publicidad de los actos de las sociedades, el TJUE señala que esta tiene por objeto garantizar la seguridad jurídica en las relaciones entre la sociedad y terce$\operatorname{ros}^{116}$. De la misma forma, el TJUE hace alusión al hecho de que, a pesar del cese de una actividad mercantil o de la liquidación de una sociedad, pueden subsistir derechos, deberes y relaciones jurídicas vinculadas a la misma, información que puede resultar necesaria a un tercero interesado en entrar en una relación comercial (vid. apartados 52 y 53). Más adelante, el TJUE analiza la cuestión relativa a los diferentes plazos de prescripción aplicables en los Estados miembros de la UE, concluyendo que resulta imposible fijar un plazo concreto, tras la liquidación de un sociedad, a partir del cual los datos de carácter personal no serían necesarios, y por ende, resultaría adecuado poder suprimirlos o limitar el acceso a los mismos; es decir un plazo concreto para ejercer el derecho al olvido digital (vid. apartados 55 y 56). Además, concluye que no cabe derivar de la Directiva de protección de datos un derecho a obtener la supresión de tales datos, o en otras palabras, un derecho al olvido digital, tras superar el registro de sociedades un examen lógico de proporcionalidad ${ }^{117}$. No obstante, el TJUE en el apartado 60 in fine y 61 de su sentencia, apunta que no cabe excluir, de manera rotunda, la posibilidad de que puedan existir razones preponderantes y legítimas en un caso concreto, que justifiquen una excepción a esta regla, permitiendo una restricción de acceso a datos personales, inscritos en un registro mercantil, al expirar un plazo concreto, lo que

115 Establecen que: "la actividad de una autoridad pública consistente en almacenar [...] datos que las empresas han de comunicar en virtud de una obligación legal, en permitir a las personas interesadas consultar dichos datos [...] incluida en el ejercicio de prerrogativas del poder público [...]”."

116 Vid. apartados 49 y 50: “[...] como garantía respecto a terceros, [...] la publicidad debe permitir a los terceros conocer los actos esenciales de la sociedad y ciertas indicaciones relativas a ella, concretamente la identidad de las personas que tienen el poder de obligarla [...] [para] que toda persona deseosa de establecer y mantener relaciones comerciales con sociedades radicadas en otros Estados miembros pueda fácilmente tomar conocimiento de los datos esenciales [...]".

117 Vid apartado 57 a 60: "imponen la publicidad únicamente de un número limitado de datos personales [...]los relativos a la identidad y las funciones respectivas de las personas que tienen poder para vincular a la sociedad de que se trate respecto de terceros [...] prevé la publicidad de los datos [...] implica un riesgo económico acrecentado para éstos [...]prevalece, en principio, la necesidad de proteger los intereses de terceros [...] y de garantizar la seguridad jurídica, la lealtad de las transacciones comerciales y, de este modo, el buen funcionamiento del mercado interior [...]". 
no se consideró justificado en este caso concreto ${ }^{118}$. Por lo tanto, la sentencia se puede resumir de la siguiente manera: en primer lugar, como regla general, y por razones imperiosas de interés general en el ámbito de los intercambios económicos, no cabe extender el derecho al olvido digital a los datos de carácter personal de las personas físicas inscritas en los registros de personas jurídicas o sociedades, $y$, en segundo lugar, que, en situaciones concretas, puede haber razones fundadas para que, excepcionalmente, se limite el acceso a datos personales tras el paso de un tiempo lo suficientemente largo.

A modo de conclusión, cabe decir que la doctrina que sienta esta sentencia parece lógica ${ }^{119}$. Repárese en que esta sentencia no aborda los límites de la utilización, por parte de terceros, de los datos que figuran en estos registros, sobre todo, teniendo en cuenta que la información personal, a pesar de figurar en un registro mercantil (1), no pierde su calificación de dato de carácter personal, definido en el nuevo RGPD y (2) dependiendo del uso que se haga del mismo, puede suponer un menoscabo grave para el libre desarrollo de la persona en cuestión.

\subsection{Aportaciones recientes de la jurisdicción española}

La jurisdicción española cuenta ya con las primeras sentencias del Tribunal Supremo, de los Tribunales Superiores de Justicia y de la Audiencia Nacional relativas a la privacidad y las nuevas tecnologías, en las que no dejan de apreciarse los diferentes criterios que pueden ser de utilidad para la resolución de conflictos sobre la "cuarta generación de derechos humanos" 120 . Además de tener garantías jurisdiccionales a nivel europeo, relativas a un derecho al olvido digital, también cabe aludir a los dos hitos jurisprudenciales de la jurisdicción española, así como a las sentencias más recientes que ya no sólo reconocen sino que también delimitan un "derecho al olvido digital". La primera sentencia, a nivel nacional, que reconoce la existencia de un derecho al olvido digital es la sentencia de 8 de febrero de 2013 de la Audiencia Provincial de Barcelona ${ }^{121}$. En esta crucial sentencia, el órgano que conocía del asunto señaló que, a pesar de que los hechos que dieron lugar a la controversia eran de interés público y de suficiente entidad como para justificar la prevalencia de las libertades informativas sobre otros derechos como la intimidad o la protección de

118 Vid. apartado 63 de la STJUE: “[...] no constituye una razón de este tipo, habida cuenta, en particular, del interés legítimo de éstos a disponer de esa información."

119 en tanto en cuanto, tanto la sentencia del Asunto Google Spain SL como las resoluciones de la AEPD sobre el derecho al olvido parecen dejar fuera de la supresión de datos personales aquellos relativos al ámbito profesional, pero, a la vez, puede suponer un riesgo.

120 Idea que, aunque no compartimos - una jerarquización de derechos humanos- defiende J. BUSTAMANTE, "Segundos pensamientos. La cuarta generación de derechos humanos en las redes digitales", TELOS, n.o 85 (Octubre - Diciembre), 2010, pp. 1-2.

121 Sentencia de la Audiencia Provincial de Barcelona (Sección 14), núm. 86/2013, que versaba sobre la difusión de datos personales, vinculados a unos antecedentes penales cancelados, en el contexto de una investigación policial, por parte de un periódico de tirada nacional, y su menoscabo para el honor, reputación, intimidad, y libre desarrollo de la personalidad del individuo en cuestión. 
datos ${ }^{122}$, el hecho de que datos identificables innecesarios para la difusión de dicha noticia se publicaran, afecta al derecho fundamental a la intimidad. Así se reconoce un derecho al olvido digital a favor del titular de los datos personales, vinculándolo a la intimidad personal. En este sentido, la sentencia de 11 de octubre de $2013^{123}$ también resulta relevante, sobre todo por la argumentación jurídica que aporta respecto a la ratione constitutionalis del derecho al olvido, que se basa "en el derecho a la privacidad o como parte de los derechos de la personalidad [...]justificado [...] en la convicción de que el ser humano no debe reducirse a su pasado[...]" (Fundamento Jurídico 4).

Por otro lado, la segunda sentencia que reconoce el derecho al olvido en España, precisamente también en la Audiencia Provincial de Barcelona, es la de 17 de julio de $2014^{124}$. Este pronunciamiento tiene una revelancia significativa dado que es la primera sentencia en España que reconoce formalmente el derecho al olvido digital, conectando las facultades de cancelación y oposición del titular de los datos, vinculándolo al derecho fundamental a la protección de datos de carácter personal. Así, el tribunal señala que el bien jurídico vulnerado por el motor de búsqueda es el "derecho al olvido" (Fundamento Jurídico 5), que resulta ser en realidad una manifestación de dos derechos de la personalidad distintos: el derecho al honor y a laintimidad personal y familiar ${ }^{125}$. Puesto que apenas dos meses antes del fallo, se publicó la sentencia del TJUE sobre el Asunto Google Spain SL, la Audiencia Provincial se inspiró en ella, tanto a la hora de interpretar el "derecho al olvido digital" como de considerar a Google como "responsable de tratamiento". Así, este órgano jurisdiccional español concluye que el carácter especialmente sensible de los antecedentes penales en la normativa de protección de datos europea y nacional, como "datos especialmente protegidos", así como los derechos de cancelación y oposición regulados tanto a nivel europeo como español, hace que exista un incumplimiento por parte del motor de búsqueda, responsable del tratamiento, de su obligación jurídica de eliminar de la lista de resultados, aquellos enlaces a páginas que contengan datos personales o información relativa a esa persona que ya no sean relevantes por el largo tiempo transcurrido, incluso cuando dichos datos no se eliminen de la página web origi-

122 Vid. Fundamento Jurídico 3: “[...] afectación del derecho a la intimidad personal, por la descontextualización de los datos [...] antiguas condenas [...]ninguna eficacia una vez producida la cancelación de antecedentes penales e inciden de forma directa en el llamado derecho al olvido [...]".

123 Sentencia de la Audiencia Provincial de Barcelona (Sección 14), núm. 1921/2013.

124 Sentencia de la Audiencia Provincial de Barcelona (Sección 16), núm. 364/2014, que versaba sobre la solicitud de interrupción del tratamiento de datos personales realizado por parte de un motor de búsqueda online, admitiendo un derecho al olvido en Internet a través de su conexión con el derecho fundamental a la protección de datos.

125 En cuanto al derecho de protección de datos, la sentencia trata de determinar si ha habido infracción del mismo por el mero hecho de que Google publique enlaces en versión electrónica del Boletín Oficial del Estado sobre un indulto, un largo tiempo después de la publicación en la versión en papel. 
naria, faltando así, a la diligencia exigible que le debería haber llevado a suprimirlos (Fundamentos Jurídicos 8 y 21$)^{126}$.

A finales de ese mismo año, la Audiencia Nacional publicó su sentencia de 29 de diciembre de $2014^{127}$, que resulta ser muy relevante por constituir el primer reconocimiento expreso que se hace del derecho al olvido digital, aplicando directamente la doctrina sentada por la sentencia del TJUE de 13 de mayo de 2014. Aunque da la misma respuesta que el TJUE, esclarece algunas dudas estableciendo los criterios para su ejercicio ${ }^{128}$. Así, la tutela del derecho de oposición de los particulares requiere una ponderación de los derechos en conflicto para establecer si el derecho a la protección de datos debe prevalecer sobre otros derechos e intereses legítimos, teniendo en cuenta la concreta situación personal y particular de la persona en cuestión (Fundamento Jurídico 11). En todo caso, y dado que en la doctrina jurisprudencial se ha asentado que ningún derecho es absoluto (Fundamento Jurídico 13) ${ }^{129}$, la cancelación de datos de carácter personal estará justificada cuando las circunstancias de cada caso concreto así lo determinen ${ }^{130}$. Además, esta resolución reconoce el derecho del usuario, titular de los datos de carácter personal a retirar los enlaces del motor de búsqueda relativos a la información publicada 16 años antes, por considerar que dicha información, a día de hoy,carecía de relevancia e interés para el público, debido al tiempo transcurrido y recordando que el hecho de eliminar los vínculos no supone una desaparición de la información, sino más bien su "desvinculación" con datos identificables de la persona, tales como su nombre (Fundamento Jurídico 14 in fine). Esta sentencia es la primera publicada de una larga lista de sentencias que reconocen un derecho al olvido de los particulares, definiéndolo como un poder de disposición sobre informaciones de carácter

126 Tal y como apuntan algunos autores como P. SIMÓN CASTELLANO, El reconocimiento del derecho al olvido, cit., p. 226., lo más interesante es, sin embargo, saber desde cuándo tiene un motor de búsqueda esta obligación. Según la SAP de Barcelona, el día relevante para fijar cuándo se comienza a producir el daño es el de la notificación a Google de la resolución de la AEPD en la que se le ordena retirar los enlaces indeseados, lo que para algunos autores, es discutible, si tenemos en cuenta que esta fecha es muy anterior al reconocimiento formal de esta facultad en el Asunto Google Spain SL. En este sentido, vid. I. GARROTE FERNÁNDEZ-DÍEZ, "Vulneración del "Derecho al Olvido" e Indemnización por Daños. Sentencia de la Audiencia Provincial de Barcelona (Sección 16ª) de 17 de julio de 2014", CESCO, 2015.

127 Sentencia de la Audiencia Nacional (Sala de lo Contencioso), núm. 725/2010.

128 Vid. Fundamento Jurídico 13 in fine. Declarando que aquel que ejercita su derecho de oposición debe indicar "que la búsqueda se ha realizado a partir de su nombre, como persona física; indicar los resultados o enlaces obtenidos a través del buscador, así como el contenido de esa información que le afecta y que constituye un tratamiento de sus datos personales [...]".

129 "[...] prevalencia del derecho de oposición [...] sobre el interés legítimo del gestor del motor de búsqueda en la actividad que desarrolla, no es absoluta [...] Al igual que la protección del derecho fundamental al respeto de la vida privada, del que la protección de datos personales constituye una manifestación autónoma, las injerencias, o límites, en este derecho pueden venir justificadas [...]".

130 Vid. Fundamento Jurídico 13: "ya sea por la naturaleza de la información, su carácter sensible para la vida privada [...]por la no necesidad de los datos en relación con los fines para los que se recogieron o por el tiempo transcurrido, entre otras [...]". 
personal que se publican(Fundamento Jurídico 13) y establece los criterios aplicables para ejercitarlo. Cabe apuntar que esta sentencia fue recurrida en casación y dio lugar a la sentencia del Tribunal Supremo de 14 de marzo de 2016, la cual ha modificado la doctrina jurisprudencial asentada por la Audencia Nacional ${ }^{131}$, en tanto en cuanto obliga a los usuarios que quieran ejercitar sus derechos a hacerlos valer contra la sede central del motor de búsqueda en cuestión ${ }^{132}$.

Si bien las sentencias de la Audiencia Provincial de Barcelona resultaban ser novedosas y relativamente proteccionistas con respecto a los derechos de los usuarios, en parte han sido revocadas por la sentencia del Tribunal Supremo de 15 de octubre de $2015^{133}$, aunque la sentencia sigue constituyendo un avance relevante en el logro de una protección plena y eficaz de los derechos de la personalidad en el entorno digital. Por esta razón, parece necesario traer a colación la sentencia del Tribunal Supremo de 5 de abril de $2016^{134}$ por su pronunciamiento sobre el derecho al olvido digital en el caso concreto, ya no sobre una hemeroteca, sino sobre la operación de buscar de un motor de búsqueda ${ }^{135}$, al asentar que el derecho al olvido sí cubre que el afectado, de no ser figura pública, se oponga al tratamiento de datos personales realizado a través de una consulta generalista en la Red, haciendo indelebles y generalmente accesibles informaciones que pueden ser gravemente dañosas para derechos fundamentales como el honor o la intimidad personal, distorsionando, así, gravemente, la percepción que de su persona terceros puedan tener yprovocando una estigmatización social (vid. Fundamento Jurídico 5, punto 13).Cumple recordar aquí que existen ya varias decenas de sentencias que han reafirmado un derecho al olvido digital en España, basándose tanto en la jurisprudencia inicial europea como en su reciente plasmación española.

131 Vid. Fundamento Jurídico 10: "no cabe hablar de corresponsabilidad de Google Spain en el tratamiento de datos en cuestión, por cuanto no concurren en la misma los requisitos que determinan la condición de responsable, y tampoco constituye título para ello la unidad de negocio que conforma con Google Inc a que se refiere la sentencia de instancia."

132 Lo que justifica con apoyo en un análisis de derecho comparado, examinando la doctrina jurisprudencial de otros países.

133 Apuntando que la adopción de medidas de eliminar datos personales del código fuente de la página web que contenía la noticia, suprimir los nombres y apellidos y no permitir que constaran siquiera las iniciales, además de adoptar medidas técnicas que evitasen que la información pudiera ser indexada por el propio buscador interno de la web del periódico suponía un "sacrificio" desproporcional y excesivo de la libertad de información. Así, aunque reconoce el vínculo entre el paso del tiempo y la intimidad informática (privacy), a través de la oposición al tratamiento de datos, precisa que este derecho no ampara que se pueda reconstruir el pasado a medida.

134 Sentencia del Tribunal Supremo, de 5 de abril de 2016, núm. de recurso 3269/2014.

135 " [...] no puede exigirse al gestor de un motor de búsqueda que [...]propia iniciativa depure [...] sacrificio desproporcionado para la libertad de información, [...] Pero sí [...] dé una respuesta adecuada a los afectados que ejerciten sus derechos de cancelación y oposición al tratamiento de datos, $[. .$.$] cuando haya transcurrido un periodo de tiempo que haga inadecuado el$ tratamiento, por carecer las personas afectadas de relevancia pública, y no tener interés histórico la vinculación de la información con sus datos personales." (Fundamento Jurídico 5, punto 13). 


\section{REFLEXIONES Y PROPUESTAS FINALES. EL YO PROTÉICO FRENTE A LA RED QUE NUNCA OLVIDA Y LA DIFÍCIL BÚSQUE- DA DE UN EQUILIBRIO COMO RETO CONSTITUCIONAL}

Históricamente, los seres humanos hemos sentido la paradójica necesidad de recordar y olvidar, y hemos tratado de buscar un equilibrio entre estas dos realidades. No obstante, parece que, con el advenimiento de la era de la pasada Web 2.0, instaurada 3.0 y estrenada $4.0^{136}$, caracterizado por la superinformación y por la memoria ilimitada de Internet, el equilibrio se convierte en un objetivo cada vez más difícil de alcanzar. En efecto, al igual que Proteo, la Red Internet no sólo lo sabe todo, sino que nunca olvida nada que constara en ella alguna vez. El ideal con el que nos dejó ROYER-COLLARD resulta de obligada referencia, en tanto en cuanto la revolución tecnológica y digital ha convertido las paredes en escaparates ${ }^{137}$, pues la sociedad actual aspira a verlo todo y saberlo todo. También lo apuntó MAYER-SCHÖNBERGER hace ya bastante tiempo:la memoria se ha convertido en la norma, y el olvido en la excepción ${ }^{138}$. Así, a pesar de las mejoras que han aportado las nuevas tecnologías, también hallamos tan nuevas como sutiles formas de "ataque" contra los derechos fundamentales, en particular la intimidad y la vida privada de las personas.

Por todo ello, resulta conveniente volver a restaurar la protección del núcleo más íntimo del ser humano, en aras de proteger la dignidad y el libre desarrollo de las personas, mediante la acción combinada del legislador y del juez. Ha surgido la aspiración a un derecho al olvido digital, frente a esta amenaza de hipertimesia inducida, que contrasta con el collage de recuerdos selectivos, más o menos borrosos, que recorren los territorios de la memoria humana. El presente estudio de los desarrollos normativos y jurisprudenciales recientes revela precisamente la voluntad del legislador y los tribunales nacionales y europeos de reconocer la existencia de un derecho al olvido digital. El debate en torno a este derecho es un debate todavía en estado embrionario, que sin duda crecerá hasta cristalizarse en prácticas sociales, construcciones jurisprudenciales y textos jurídicos proporcionados y justos ${ }^{139}$. El derecho al olvido se podría calificar como la protección de la persona contra la inviolabilidad de su pasado o de la percepción que terceros tengan de ella y difundan por la Red Internet: en el escenario práctico, se configura como un poder de control sobre los datos de carácter personal con el fin de proteger la dignidad y el libre desarrollo personal contra el resurgimiento perjudicial que puede suponer un clic instantáneo y una memoria digital que nunca olvida.

136 A. TOURIÑO, El derecho al olvido y a la intimidad, cit. p. 17-20.

137 P. ROYER-COLLARD, Citado por B. REY, La vie privée à l'ère du numérique, Lavoisier, Cachan, 2012, p. 45-47.

138 V. MAYER-SCHÖNBERGER, Delete. The Virtue of Forgetting in the Digital Age, Princeton University Press, New Jersey, pp. 135-144.

139 J.M. MARTÍNEZ OTERO, "El derecho al olvido en Internet: debates cerrados y cuestiones abiertas tras la STJUE Google vs AEPD y Mario Costeja", Revista de Derecho Político UNED, n.o 93 (mayo-agosto), 2015, p. 134. 
La regulación del derecho al olvido digital no protege únicamente la vida privada en su faceta de la intimidad informática o privacidad, sino también la autonomía personal (en lo que respecta al control de los datos personales). Los sistemas constitucionales, tanto a nivel normativo como jurisprudencial, se están viendo forzados a abordar estas cuestiones a través de las cláusulas relativas al orden axiológico fundamental (asentado en la dignidad de la persona) y la apertura a los estándares europeos e internacionales en materia de derechos humanos, frente a las libertades informativas reconocidas. En este sentido, se consagra bajo los dos principios rectores de todo ordenamiento: la libertad y la dignidad ${ }^{140}$. En efecto, la dignidad, inextricablemente ligada a los derechos de la personalidad, puede verse afectada por esa memoria sin límites, por la difusión global y el recuerdo constante de hechos o datos pasados, quedando el derecho al olvido digital como protector de un bien jurídico más amplio, que garantiza la libertad y la autonomía del individuo de actuar y desarrollar su proyecto vital, tesis de SIMÓN CASTELLANO, la cual suscribimos ${ }^{141}$. El derecho al olvido, en definitiva, podría considerarse el derecho de cada persona a determinar su existencia, obteniendo un respeto a su vida privada, por parte de los demás, también en el contexto digital. Así lo apuntó también el Presidente de la Comisión Europea Jean-Claude Juncker en su discurso sobre el estado de la unión de 2016: "En Europa, valoramos la intimidad: es una cuestión de dignidad humana" ${ }^{142}$.

Que el 'olvido digital' existe y es un derecho resulta, a estas alturas,indiscutible. No obstante, sí es cierto que todavía no nos encontramos ante un concepto jurídico "pacíficamente delimitado" 143 ; también es cierto que los derechos valen tanto como las garantías y que, por tanto, es preciso pasar del mero reconocimiento a una implementación y protección efectivas. Y, sin embargo, el derecho al olvido, en la práctica, tiene determinadas características, y se enfrenta a determinados obstáculos que hacen difícil hacerlo efectivo: por un lado, la imposibilidad técnica de borrar hasta el último rastro que dejamos en Internet, y por otro, su enfrentamiento con las libertades informativas, como la libertad de expresión, el derecho de información o el deber de transparencia. WILLIAM MALCOLM, Consultor Senior sobre Privacidad de Google, ya apuntó que, aunque el derecho al olvido se ha ratificado como derecho fundamental, su enfrentamiento con la libertad de expresión, también de rango fundamental, requiere de un equilibrio ${ }^{144}$. Surgen, en efecto, conflictos inevitables entre derechos: entre la seguridad y la libertad, la protección de la vida privada y la

140 Así lo ha apuntado también SIMÓN CASTELLANO "El derecho al olvido se ha venido configurando como un derecho de autonomía y libertad, que encuentra su fundamento constitucional en la dignidad humana y el libre desarrollo de la personalidad" en P. SIMÓN CASTELLA$\mathrm{NO}$, "El régimen constitucional del derecho al olvido en Internet", en A. Cerrillo I Martínez et al (coords.): Neutralidad de la red y otros retos para el futuro de Internet. Barcelona: UOC-Huygens, 2011, p. 391 a 406, así como en P. SIMÓN CASTELLANO, El régimen constitucional del derecho al olvido, cit., p.121.

141 P. SIMÓN CASTELLANO, El régimen constitucional del derecho al olvido, cit., p.123.

142 Vid. http://europa.eu/rapid/press-release_SPEECH-16-3043_es.htm

143 A. RALLO LOMBARTE, El derecho al olvido en Internet, cit., p. 17.

144 Vid. http://tecnologia.elderecho.com/tecnologia/privacidad/William-Malcolm-Googleprivacidad-seguridad-internet-derecho-olvido_14_874570001.html 
libertad de expresión, el derecho a la información y el derecho a la intimidad, entre otros muchos; en otras palabras, se nos plantea un conflicto inherente a cualquier sociedad, entre los derechos individuales, las libertades colectivas y el interés general. Es precisamente ante estos obstáculos jurídicos y estos miedos a la censura y a la reinvención de la historia, que debe repensarse un equilibrio, así como articularse criterios de ponderación, que actualicen principios tradicionales como el principio de proporcionalidad, al tiempo que reformulan la noción de interés público.Por otro lado, los obstáculos técnicos a la aplicación efectiva del derecho al olvido digital radican en la ya mencionada "imposibilidad" técnica de eliminar totalmente la información de la Red Internet.Al menos habría que asegurar y delimitar su destino y las condiciones potenciales de su descubrimiento, dada la proliferación de métodos de duplicación en términos de almacenamiento de datos y posibilidades tecnológicas, como, entre otras, la 'geolocalización' y las 'etiquetas'. Para conseguir este objetivo, no solo se requiere un perfeccionamiento a nivel jurídico-constitucional, sino también socio-tecnológico, basado en la sensibilización de los usurios de Internet (a ser más diligentes en su uso de las NTIC), y a las empresas, sobre todo los gigantes digitales, a seguir unos códigos de buenas prácticas, que respeten las protección de datos de carácter personal, así como establecer medidas más seguras para la protección de la intimidad informática ${ }^{145}$.

Así pues, se ha optado por la consideración de la protección de datos como un verdadero derecho fundamental, que requiere un inexorable acercamiento a la dignidad, y concretamente al derecho a la intimidad, como construcciones jurídicas previas y centrales, lo que no significa una dependencia o subordinación entre ellos. Su vertiente, reconocida como el derecho al olvido digital, a la que cada vez se le da una protección más elevada dada su posición actual como el derecho por excelencia de la era informática, se puede configurar como un derecho subjetivo y autónomo en potencia, derivado de la dignidad humana y de los derechos de la personalidad. En suma, gozamos de un marco jurídico exhaustivo con derechos bien consagrados, pero ello requiere una efectiva implementación. Todo lo cual muestra, en última instancia, la complejidad del marco regulatorio de la protección de datos, en general, y del derecho al olvido digital, en particular, en el seno del CdE, de la UE, y en España, tal y como se ha expuesto en el presente trabajo, que ha procurado destacar las garantías jurídicas y los retos que se interponen en la salvaguarda del derecho al olvido digital, a través del estudio de los sistemas de protección, normativos y jurisprudenciales, de los derechos humanos en Europa.

145 Como, por ejemplo, la 'anonimación' de datos o la adopción de un modelo de privacidad desde el diseño y por defecto, que regula el artículo 25 del RGPD. No obstante, esta nueva regulación asume que las organizaciones y las empresas puedan desarrollar nuevos sistemas y procesos de gestión que permitan incorporar las nuevas obligaciones impuestas por la normativa europea y española, pero a día de hoy, la mayor parte de las empresas afectadas, sobre todo las más pequeñas, no están preparadas, ni técnica ni económicamente para garantizar tal nivel de gestión o para rediseñar completamente sus políticas de negocio y sus modelos de funcionamiento, lo cual generará nuevos retos en un futuro a corto y medio plazo. 


\section{BIBLIOGRAFÍA FINAL}

ACQUISTI, A., TAYLOR C. y WAGMAN, L., "The economics of privacy", Journal of Economic Literature, n.o. 54: 2, 2016, pp. 442-492.

ÁLVAREZ CANO, M., Derecho al olvido en Internet: el nuevo paradigma de la privacidad en la era digital, Reus, Madrid, 2015, p. 27.

ARANDA SERRALBO, J., Right to oblivion: A way to get to know ourselves and share the knowledge, Londres, 2013, p. 47.

ARENAS RAMIRO, M., "Unforgettable: a propósito de la STJUE de 13 de mayo de 2014.Caso Conseteja (Google v. AEPD)", Teoría y Realidad Constitucional, n.o. 34, 2014, pp. 552-553.

ARENAS RAMIRO, M., El derecho fundamental a la protección de datos personales en Europa, Tirant lo Blanch, Valencia, 2006.

AZURMENDI, A., "Por un derecho al olvido para los europeos: aportaciones jurisprudenciales de la Sentencia del Tribunal de Justicia Europeo del caso Google Spain y su recepción por la Sentencia de la Audiencia Nacional Española de 29 de diciembre de 2014", Revista de Derecho Político (UNED), n.o 92, 2015, pp. 273-310.

BUSTAMANTE, J., "Segundos pensamientos. La cuarta generación de derechos humanos en las redes digitales", TELOS, n.o 85 (Octubre-Diciembre), 2010, pp. 1-2.

CARNEROLI, S., Le droit à l'oubli. Du devoir de mémoire au droit à l'oubli, Larcier, Bruselas, 2016, p. 72

CEREZO, J.M., "Hacia un nuevo paradigma. La era de la información fragmentada", Revista TELOS, n.o 76 (julio-septiembre), 2008, pp. 1-8.

CÓRDOBA CASTROVERDE D. e DÍEZ-PICAZO GIMÉNEZ, I. "Reflexiones sobre los retos de la protección de la privacidad en un entorno tecnológico", Cuadernos y Debates, n.o. 248: El derecho a la privacidad en un nuevo entorno tecnológico, Madrid, Centro de Estudios Políticos y Constitucionales, 2016, p. 107.

COTINO HUESO, L., "La STJUE del caso google vs AGPD de 2014. Algunos "olvidos" y otras tendencias negativas respecto de las libertades informativas en internet", ponencia en Seminari interdepartamental de la Facultat de Dret de València.

COTINO HUESO, L., "La colisión del derecho a la protección de datos personales y las libertades informativas en la red: pautas generales y particulares de solución", en L. Cotino Hueso (ed.), Libertades de expresión e información en Internet y las redes sociales: ejercicio, amenazas y garantías, Publicaciones de la Universidad de Valencia, Valencia, 2011, p. 386 a 401.

DEL FRESNO GARCÍA, M., "Internet como macromedio. La cohabitación entre medios sociales y medios profesionales", TELOS: Cuadernos de comunicación e innovación, n.o. 99, 2014, (octubre-enero), pp. 107-109.

GALETTA, A., y DE HERT, P. "A European perspective on data protection and access rights", en C. Norris y X. L'hoiry (Coords.), Deliverable D5: Exercising democratic rights under surveillance regimes, pág. 8. Disponible en: http://irissproject.eu/ wp-content/uploads/2014/06/European-level-legal-analysis-Finall.pdf 
GARROTE FERNÁNDEZ-DÍEZ, I., "Vulneración del "Derecho al Olvido" e Indemnización por Daños. Sentencia de la Audiencia Provincial de Barcelona (Sección 16a) de 17 de julio de 2014", CESCO, 2015. Disponible en:http://blog. uclm.es/cesco/files/2015/02/Vulneraci\%C3\%B3n-del-derecho-al-olvido-eindemnizaci\%C3\%B3n-por-da\%C3\%B1os.pdf

GHEZZI, A., GUIMARES PEREIRA A. y VESNIC-ALUJEVIC, L., The ethics of memory in a digital age: interrogating the right to be forgotten, Londres, Palgrave Macmillan memory studies, 2014, p. 11.

GOMES DE ANDRADE, N.N., "El olvido: El derecho a ser diferente... de uno mismo Una reconsideración del derecho a ser olvidado", En: VII Congreso Internacional Internet, Derecho y Política. Neutralidad de la red y otros retos para el futuro de Internet [monográfico en línea], IDP. Revista de Internet, Derecho y Política, n.o 13, 2012, pp. 67-83. Disponible en: http://www.raco.cat/index.php/IDP/article/ viewFile/251843/337493

GONZÁLEZ FUSTER, G., The Emergence of Personal Data Protection as a Fundamental Right of the EU, Springer, Bruselas, 2015, p. 55-71.

GONZÁLEZ FUSTER, G., “TEDH - sentencia de 04.12.2008, y S. Marper c. Reino unido, 30562/04 y 30566/04 - artículo $8 \mathrm{CEDH} \mathrm{-} \mathrm{vida} \mathrm{privada} \mathrm{-} \mathrm{injerencia} \mathrm{en} \mathrm{una}$ sociedad democratica - los límites del tratamiento de datos biométricos de personas no condenadas", Revista de Derecho Comunitario Europeo, n.o 33, 2009, pp. 619-633

JIMENA QUESADA, L., “Crónica de la Jurisprudencia del Comité Europeo de Derechos Sociales - 2010”, Revista Europea de Derechos Fundamentales, n.o 16, 2014, p. 385-407.

JIMENA QUESADA, L., "La Carta de Derechos Fundamentales de la UE: rango legal y contenidos sustantivos", Cuadernos europeos de Deusto, n.o 40, 2009, p. 63.

KUNER, C., "The Court of Justice of the EU Judgment on Data Protection and Internet Search Engines", LSE Law, Society and Economy Working Papers, n.o 3, 2015, p. 21.

LÓPEZ PORTAS, M.B., "La configuración jurídica del derecho al olvido en el derecho español a tenor de la doctrina del TJUE”, Revista de Derecho Político (UNED), n.o 93 (mayo-agosto), 2015, p. 147.

MARTÍNEZ MARTÍNEZ, R., "Cuestiones de ética jurídica al abordar proyectos de Big Data. El contexto del Reglamento general de protección de datos", Dilemata n.o. 24, 2017, 151-164.

MARTÍNEZ MARTÍNEZ, R., “Aplicar el derecho al olvido”, Revista Aranzadi de Derecho y Nuevas Tecnologías, n.o. 36, 2014, pp. 121-142.

MARTÍNEZ MARTÍNEZ, R., “¿Quién debería olvidarnos en Internet?”, Revista jurídica Aranzadi, n.o.857, 2013, p. 11.

MARTÍNEZ OTERO, J.M., "El derecho al olvido en Internet: debates cerrados y cuestiones abiertas tras la STJUE Google vs AEPD y Mario Costeja", Revista de Derecho Político UNED, n.o 93 (mayo-agosto), 2015, p. 134. 
MAYER-SCHÖNBERGER V. y CUKIER, K., Big Data: A Revolution That Will Transform How We Live, Work, and Think, John Murray Publishers, Londres, 2013.

MAYER-SCHÖNBERGER, V., Delete. The Virtue of Forgetting in the Digital Age, Princeton University Press, New Jersey, 2009, pp. 135-144.

NOAIN SÁNCHEZ, A., La protección de la intimidad y vida privada en internet: la integridad contextual y los flujos de información en las redes sociales (2004-2014), Agencia Española de Protección de Datos, Madrid, 2016, p. 77-106.

ORDOÑEZ SOLÍS, D., La protección judicial de los derechos en internet en la jurisprudencia europea, Reus, Madrid, 2014, p. 22.

ORZA LLINARES R.M. y RUIZ TARRÍAS, S., "El derecho al olvido en Internet” en A. Cerrillo I Martinez, M. Peguera, I. Peña López y M. Vilasau Solana (Coords.), Neutralidad de la red y otros retos para el futuro de Internet, UOC-Huygens, Barcelona, 2011, pp. 380-389.

PAZOS CASTRO, R., El mal llamado “derecho al olvido" en la era de Internet, Boletín del Ministeriode Justicia (Estudio doctrinal), n.o 2138, 2015, p. 6.

PEREZ LUÑO, A.E., Derechos humanos, Estado de Derecho y Constitución, 10a ed., Madrid, Tecnos, 2010, p. 361.

RALLO LOMBARTE, A., El derecho al olvido en Internet. Google versus España, Madrid, Centro de Estudios Políticos y Constitucionales, 2014, p. 17.

RALLO LOMBARTE, A., "Caso Google vs. España. Sentencia del TJUE 13 de mayo de 2014: La garantía del derecho al olvido en internet", Actualidad Jurídica Aranzadi, n.o 886, 2014, pp. 8-9.

RALLO LOMBARTE, A., "Hacia un nuevo sistema europeo de protección de datos: las claves de la reforma”, Revista de Derecho Político (UNED), n.o 85 (septiembrediciembre), 2012, p. 17 y ss.

RALLO LOMBARTE, A., “A partir de la protección de datos. El derecho al olvido y su protección”, TELOS, n.o 85 (Octubre - Diciembre), 2010, p. 5.

REBOLLO DELGADO, L., El derecho fundamental a la intimidad, Dykinson, Madrid, 2005 , p. 365.

RODOTÀ, S., El derecho a tener derechos, Bolonia, Trotta, Trad. de J. REVUELTA LÓPEZ, 2014, p. 172.

ROYER-COLLARD, P., Citado por B. REY, La vie privée à l'ère du numérique, Lavoisier, Cachan, 2012, p. 45-47.

SABHERWAL R. y BECERRA-FERNANDEZ, I., Business Intelligence Practices, Technologies and Management, Hoboken, John Wiley \& Sons, 2011, pp. 6-8.

SANCHO LÓPEZ, M., "Nuevas amenazas para la protección de datos en el contexto del Big Data", Revista Aranzadi de Derecho y Nuevas Tecnologías, n.o. 43 (eneroabril), 2017, p. 5.

SERRANO PÉREZ, M.M., El derecho fundamental a la protección de datos. Derecho español y comparado, Thomson Civitas, Madrid, 2003, p. 89. 
SIMÓN CASTELLANO, P., El régimen constitucional del derecho al olvido digital, Tirant lo Blanch, Valencia, 2012, p. 38.

SIMÓN CASTELLANO, P., El reconocimiento del derecho al olvido digital en España y en la UE. Efectos tras la sentencia del TJUE de mayo de 2014, Bosch, Barcelona, 2015, p. 300-302.

SIMÓN CASTELLANO, P., "El régimen constitucional del derecho al olvido en Internet”, en A. Cerrillo I Martínez et al (coords.): Neutralidad de la red y otros retos para el futuro de Internet. Barcelona: UOC-Huygens, 2011, p. 391 a 406.

SIMÓN CASTELLANO, P., "El derecho al olvido en el universo 2.0”, Textos universitaris de biblioteconomia i documentació -Universitat de Barcelona, n.o 28, 2012. Disponible en: http://bid.ub.edu/28/simon2.htm

STANTON, S., "Neuromarketing: Ethical Implications of its Use and Potential Misuse", Journal of Business Ethics, 2016, pp. 1-13. Disponible en: https://link.springer. com/content/pdf/10.1007\%2Fs 10551-016-3059-0.pdf

SUÁREZ VILLEGAS, J.C., "El derecho al olvido, base de tutela de la intimidad. Gestión de los datos personales en la Red", TELOS (Febrero - mayo), 2014, p. 2.

TOMÁS MALLÉN, B., "Privacidad versus seguridad en el ámbito europeo”, en A. Fayos Gardó y P. Conde Colmenero (coords.), Los derechos a la intimidad y a la privacidad en el siglo XXI, Dykinson, Madrid, pp. 215-241.

TOURIÑO, A., El derecho al olvido y a la intimidad en internet, Los Libros de la Catarata, Madrid, 2014, p. 24.

TRONCOSO REIGADA, A., "El derecho al olvido en Internet a la luz de la propuesta de Reglamento General de Protección de Datos Personales", Revista de la Agencia de Protección de Datos de la Comunidad de Madrid, n.o 59, 2012, pp. 62-74.

VILASAU SOLANA, M., "El caso Google Spain: la afirmación del buscador como responsable del tratamiento y el reconocimiento del derecho al olvido (análisis de la STJUE de 13 de mayo de 2014”, Revista de Internet, Derecho y Política (IDP) de la UOC, n.o 18, 2014, p. 24. 